\title{
Hemoconcentration and Hemostasis During Acute Stress: Interacting and Independent Effects
}

\author{
Anthony W. Austin, M.A. • \\ Stephen M. Patterson, Ph.D. • Roland von Känel, M.D.
}

Published online: 12 May 2011

(C) The Society of Behavioral Medicine 2011

\begin{abstract}
Background Acute psychological stress can produce significant hemoconcentration as well as prothrombotic changes in blood, both of which may have potentially harmful effects on the cardiovascular system. It is unclear whether these effects are independent or have influence on each other.

Purpose This review discusses research investigating the effects of acute psychological stress on hemoconcentration and hemostasis and explores future directions for psychohematology research. Physiology, associations with cardiovascular disease, and relationships between acute psychological stress are discussed independently for hemoconcentration and hemostasis, followed by an examination of the effects of stress-hemoconcentration on hemostasis.

Conclusions Traditional methods of adjusting for stresshemoconcentration effects (e.g., calculated plasma volume or hematocrit level corrections) may not be appropriate when examining stress-induced changes in hemostasis. The effects of acute stress on hemostasis should be examined in conjunction with hemoconcentration.
\end{abstract}

Keywords Hemostasis $\cdot$ Hemoconcentration .

Cardiovascular disease $\cdot$ Psychological stress

Electronic supplementary material The online version of this article (doi:10.1007/s12160-011-9274-0) contains supplementary material, which is available to authorized users.

A. W. Austin $(\bowtie) \cdot$ S. M. Patterson

Department of Psychology, Ohio University,

Athens, OH, USA

e-mail: Anthony.W.Austin.1@ohio.edu

R. von Känel

Department of General Internal Medicine,

Inselspital (University Hospital Berne),

Berne, Switzerland

\section{Introduction}

Cardiovascular disease is the underlying cause of $36 \%$ of all deaths in the USA, making it the nation's number one killer, with coronary heart disease (CHD) being the primary cause of death [1]. Several risk factors have been identified for CHD, but five have been recognized as conferring the most risk: high blood pressure, elevated serum cholesterol, body mass index, diabetes, and smoking [2]. However, these traditional risk factors do not fully explain CHD risk [3]. Psychological stress is one factor purported to explain additional CHD risk. For example, in the INTERHEART study [4], individuals with myocardial infarction reported more financial stress, more stress at home and at work, and a greater number of major life events in the previous year compared to controls. However, physiological mechanisms linking stress to CHD have yet to be delineated fully. One possible mechanism through which stress may be linked to CHD is through adverse effects on hemostasis, which is the arrest of bleeding by the physiological properties of vasoconstriction and coagulation or the interruption of blood flow through any vessel or to any anatomical area, and hemostatic processes such as platelet function [5, 6], hemorheology [7-9], and coagulation [10, 11]. In fact, elevations in several factors involved in hemostasis, such as fibrinogen, D-dimer, von Willebrand factor, and factor VII (FVII), FVIII, FIX, FXI, and FXII, have been reported as heightened risk markers for CHD [12, 13].

The initiation of acute coronary syndromes (especially myocardial infarction) and acute atherothrombotic events in the coronary tree has been linked to acute psychosocial stress that can result from negative emotions, taxing social situations, and traumatic events [11]. Several pathophysiological mechanisms have been suggested, including hemoconcentration (i.e., when the ratio of blood cells to plasma 
increases), alterations in blood rheology [7], vascular endothelial dysfunction coupled with vasoconstriction, proinflammatory cytokine release, autonomic imbalance (e.g., alterations in heart rate variability), and activation of the coagulation cascade as well as indirectly through changes in health behaviors [14-16]. The disruption of the hemostatic balance (i.e., balance between clot formation and clot dissolution) is a critical factor in atherosclerotic development and initiation of acute coronary syndromes. After plaque rupture, a vessel occlusion is more likely if the ratio of prothrombotic activity (i.e., promoting clot formation) to fibrinolytic activity (i.e., promoting clot dissolution) is high. During acute psychological stress, both prothrombotic and fibrinolytic activities increase, but with the former to a greater extent than the latter [10]. In a healthy person, such a response is physiologically normal. However, this type of response could have life-threatening effects in a patient with CHD because stress-hypercoagulability seems to be exaggerated in these patients [17] and could add to hypercoagulability initiated after plaque rupture. Therefore, risk increases for the formation of a clot large enough to critically occlude the coronary artery. The ensuing net hypercoagulability resulting from acute psychological stress may put an individual at a greater risk for coronary thrombosis after plaque disruption and thus contribute to acute coronary syndromes [10, 11]. Other crucial factors suggested to accompany hypercoagulation are stress-induced hemoconcentration [18] and increased blood viscosity [9, 19], both of which exacerbate the shear stresses imposed by atherosclerotic plaques and plaque ruptures [7]. Elucidation of how these mechanisms occur is central to understanding the relationship between stress and CHD.

The purpose of this review is to provide an update on the state of the research investigating the effects of acute psychological stress on hemoconcentration and hemostasis and to explore future directions for psychohematology research. This review has two main sections: "Hemoconcentration" and "Hemostasis". The first section provides an overview of hemoconcentration with a discussion of physiology, association with cardiovascular disease, and relationships between hemoconcentration and acute psychological stress. The second section is organized similarly, providing an overview of hemostasis with a discussion of physiology, association with cardiovascular disease, and relationships between hemostasis and acute psychological stress, with particular emphasis on coagulation. Finally, studies examining the effects of stresshemoconcentration on hemostasis are reviewed and future directions are discussed.

Research articles with human participants were identified through the use of a PUBMED search and through checking the references of these sources. The following keywords were used in various combinations for searching: psychological stress, mental stress, hemoconcentration, plasma volume, hemostasis, blood coagulation, and cardiovascular disease. Given that the focus of this review is on acute stress, articles were then examined to exclude those focusing on naturalistic stressors (e.g., earthquakes), chronic stress, vital exhaustion, or related concepts. Additionally, a wide variation in methodology existed among acute stress studies, making a systematic review difficult. Therefore, the review is narrative in nature.

\section{Hemoconcentration}

Hemoconcentration refers to conditions in which the ratio of cellular components (principally red blood cells) of the blood to the plasma volume increases [7]. Hemoconcentration mainly occurs in two ways. First, plasma volume can remain constant while the number of red blood cells increases. This condition is seen in polycythemia vera, a rare tumorous condition in which red blood cells are produced to a greater extent than normal [20] and in secondary polycythemia which is associated with altitude sickness [21]. Second, and more commonly, hemoconcentration occurs when the number of red blood cells remains constant while plasma volume decreases. This condition has been variously referred to as 'stress' polycythemia, relative polycythemia, pseudopolycythemia, spurious polycythemia, or stress-hemoconcentration [7, 22, 23]. Figure 1 depicts stress-hemoconcentration that occurs when plasma moves or shifts from the vascular compartment into interstitial spaces during acute psychological stress produced by various laboratory stressors (e.g., mental arithmetic, Stroop color-word recognition test, cold pressor test, and public speaking). Early studies of plasma volume shifts demonstrated this phenomenon during various psychological states such as emotional stress [24] and anxiety [25]. Additionally, acute psychological stress reliably elicits plasma volume losses from the vasculature [26].

\section{Hemoconcentration Assessments}

\section{Plasma Proteins}

One indicator of stress-hemoconcentration is an increase in the concentration of plasma proteins, such as serum albumin. Plasma passes easily into interstitial spaces through minute openings or pores in the capillaries. On the other hand, plasma proteins are large and pass through these pores with great difficulty, if at all [7]. Specifically, molecules greater than $69 \mathrm{kDa}$, including plasma proteins, seem to be unable to passively pass through capillary pores [27] and, as such, are susceptible to hemoconcentration [28]. Notably, the presence of these large molecules creates a large colloidal osmotic pressure gradient. Colloid osmotic pressure refers to the force that occurs when particles 


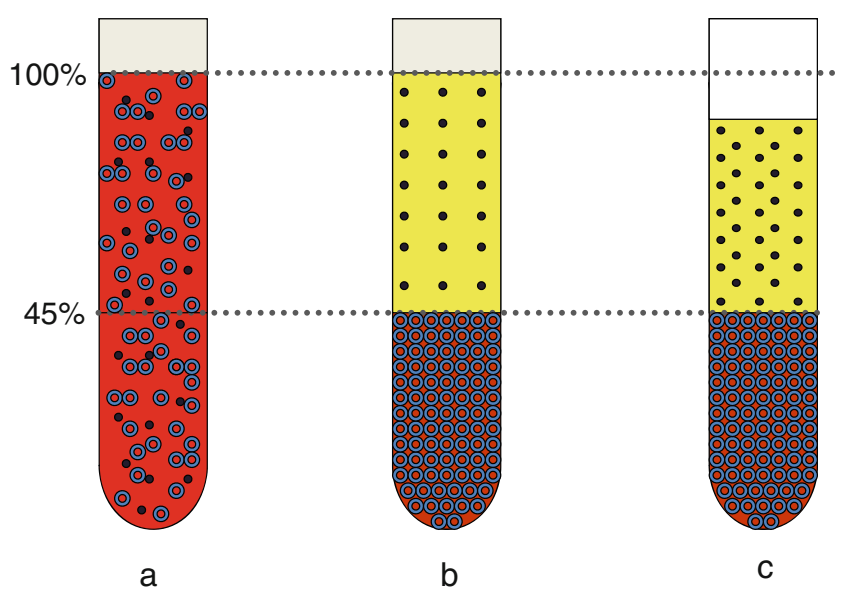

Fig. 1 Plasma volume loss and stress-hemoconcentration. a Normal whole blood. b Normal blood that has been centrifuged. Red blood cells become packed at the bottom of the tube. Plasma and non-diffusible blood components remain at the top of the tube. c Stresshemoconcentrated blood that has been centrifuged. The volume of red blood cells remains constant, but plasma volume decreases with a resultant increase in the concentration of non-diffusible blood components

cannot diffuse equally over intra- and extracapillary fluids. In the case of stress-hemoconcentration, which is facilitated by an acute increase in blood pressure and a net efflux of plasma into the interstitial spaces, the plasma protein concentration is greater inside the blood vessels than in the interstitial fluid surrounding the blood vessels, resulting in a constant pressure gradient for fluid to be drawn back into the blood vessels when blood pressure returns to normal. Therefore, an acute increase in colloid osmotic pressure as well as in the plasma protein concentration can signify stress-hemoconcentration [7, 9, 29].

A consequence of an increase in colloid osmotic pressure and plasma protein concentration is altered flow properties of the blood. Specifically, blood becomes thicker and more viscous. When plasma shifts into interstitial spaces, the resultant increase in total plasma protein concentration causes an increase in blood and plasma viscosity. Whole blood viscosity, in turn, is determined mainly by plasma viscosity, the deformability of the red cells, the extent of cellular aggregation, and the concentration of suspended particles, particularly fibrinogen. Increased blood viscosity ultimately contributes to blood pressure by increasing total peripheral resistance $[7,30]$.

\section{Hematocrit, Hemoglobin, and Plasma Volume}

Two other commonly reported indicators of the extent of stresshemoconcentration are hematocrit and hemoglobin. Hematocrit is the percentage of whole blood that is made up of red blood cells [7]. In healthy adults during rest, hematocrit ranges from $40 \%$ to $55 \%$ in males and $36 \%$ to $48 \%$ in females [31]. Hemoglobin concentration is closely related to hematocrit.
Hemoglobin is an oxygen-carrying molecule present in red blood cells. Red cells are able to carry up to $34 \mathrm{~g}$ of hemoglobin per $100 \mathrm{ml}$ of cells [20]. Consequently, the total amount of hemoglobin is determined by hematocrit and the quantity of hemoglobin in each cell. Normal adult concentrations range from 13 to $18 \mathrm{~g} / \mathrm{dl}$ in males and 12 to $16 \mathrm{~g} / \mathrm{dl}$ in females. In healthy individuals, the amount of hemoglobin carried by each red blood cell is near the maximum (i.e., $34 \mathrm{~g}$ per $100 \mathrm{ml}$ of cells), so changes in hematocrit yield nearparallel changes in hemoglobin concentration [20].

Plasma viscosity and total plasma protein concentration are considered direct measures of hemoconcentration. Calculated plasma volume from hematocrit and hemoglobin, on the other hand, is an indirect measure of hemoconcentration. Calculated plasma volume is very closely related to plasma viscosity; therefore, correction factors based on calculated plasma volume are often used to assess hemoconcentration [7, 32]. Early researchers assumed that, under conditions of constant red cell volume, a decrease in hematocrit corresponded to a proportionally equal increase in plasma volume [33, 34]. Research in the 1970s, however, suggested that hematocrit and plasma volume were not as proportional as were earlier predicted [35], and therefore hematocrit has not been shown to be directly related to plasma volume. Rather, hematocrit is the ratio of red cell volume to blood volume. For changes in hematocrit to accurately reflect changes in plasma volume, it is necessary that two assumptions are met [36]. First, the number of red blood cells must remain constant. In other words, red blood cells should not be added to or removed from the blood during the period under examination. Second, the volume of red blood cells must remain constant. However, as plasma volume decreases, the concentration of plasma proteins increases with a resultant increase in plasma osmolarity. As a result of an increase in osmolarity, fluid may move out of the red blood cells, thus diminishing their size. Put differently, events that change plasma osmolarity should also change red cell volume, which discredits the use of only hematocrit for estimating changes in plasma volume [36]. To more accurately estimate changes in plasma volume, Costill and colleagues [37-39] showed that such estimations should incorporate both hematocrit and hemoglobin. Dill and Costill [39] developed an equation that has been widely used for estimating plasma volume shifts from changes in both hematocrit and hemoglobin values:

$$
\begin{aligned}
& \mathrm{BV}_{2}=\left(\mathrm{BV}_{1}\right)\left(\mathrm{Hgb}_{1} / \mathrm{Hgb}_{2}\right) \\
& \mathrm{CV}_{2}=\left(\mathrm{BV}_{2}\right)\left(\mathrm{Hct}_{2} / 100\right) \\
& \mathrm{PV}_{2}=\mathrm{BV}_{2}-\mathrm{CV}_{2} \\
& \Delta \mathrm{PV}, \%=(100)\left(\mathrm{PV}_{2}-\mathrm{PV}_{1}\right) / \mathrm{PV}_{1}
\end{aligned}
$$

where $\mathrm{BV}=$ blood volume, $\mathrm{CV}=$ red cell volume, $\mathrm{PV}=$ plasma volume, $\mathrm{Hgb}=$ hemoglobin, $\mathrm{Hct}=$ hematocrit, 
subscript 1 refers to baseline sample, subscript 2 refers to stressor (mental or physical) sample, $\mathrm{BV}_{1}$ is taken as 100 , and $\mathrm{PV}_{1}$ is $100-\mathrm{Hct}_{1}$.

Given that the conditions employed by Costill and colleagues were rather severe (i.e., maximal exercise and severe dehydration), Greenleaf et al. [36] examined whether the addition of hemoglobin was indeed necessary to estimate plasma volume shifts resulting from less extreme conditions. Under conditions causing modest changes in plasma osmolarity (i.e., short-term heat exposure and orthostasis), hematocrit by itself estimated plasma volume changes as well as those made from the Dill and Costill [39] equation. That is, the change in the size of red blood cells was not significant [36]. Furthermore, Patterson and colleagues [40] found that, while plasma volume decreased during acute psychological stress (mental arithmetic), no changes were observed for red blood cell size (mean corpuscular volume) during the same stressor. Although the result of these studies suggest that hematocrit alone may be suitable for assessing hemoconcentration, researchers examining stress-hemoconcentration effects continue to use the Dill and Costill equation to ensure the most accurate approximations of plasma volume shifts by accounting for possible variations in red cell sizes and fluid volume.

\section{Hemoconcentration and Coronary Heart Disease}

It is valuable to examine factors that influence hemoconcentration given the close relationship between hemoconcentration and blood pressure and given that hematocrit seems to be an independent risk factor for all-cause mortality, CHD, and hypertension [41-45]. For example, logistic regression analyses suggest that hematocrit explains up to $13 \%$ of the variance in CHD incidence [42] and $10 \%$ of the variance in blood pressure in those with and without hypertension [45] beyond that associated with traditional risk factors (e.g., overweight, diabetes, and smoking).

Several epidemiological studies have indicated that hematocrit is predictive of CHD. For example, in the Puerto Rico Heart Health Program [41, 42], hematocrit at baseline in middle-aged men was related to all-cause mortality over 8 years. However, hematocrit was related to the incidence of myocardial infarction or death from acute coronary events only among urban dwellers, but not among rural inhabitants. Specifically, after adjustment for coexisting risk factors, an urban man with a hematocrit of $50 \%$ would have had a $50 \%$ higher chance of an incident coronary event during the 8-year follow-up than an urban man with a hematocrit of $40 \%$. The authors speculated that this relationship was not observed in rural individuals because a smaller relative sample was used (2,369 rural vs. 5,720 urban residents; 42). Nevertheless, the possibility that cultural variations accounted for the observed effects cannot be eliminated entirely by low statistical power. More recently, Kunnas and associates [46] compared the risks for CHD events among Finnish men with hematocrit greater than or equal to 50 to men with hematocrit less than 50. Men with lower hematocrit had better survival rates than those with higher hematocrit. Likewise, men with hematocrit greater than 50 had a 1.8-fold increased risk of death from CHD events compared to those with hematocrit less than 50 [46]. Elevated hematocrit relative to normal hematocrit probably puts an individual at a greater risk for acute coronary syndromes and may exert its effects through increased whole blood viscosity.

Epidemiological and laboratory studies also suggest that elevated hematocrit and contracted plasma volume are related to essential hypertension. For instance, in the Gubbio Population Study [43], the resting hematocrit levels were significantly higher in untreated hypertensive individuals compared to normotensive individuals. Furthermore, after adjustment for traditional risk factors, hematocrit showed an independent association with systolic (SBP) and diastolic (DBP) blood pressure. Several studies have also shown a lower plasma volume to be related to essential hypertension [47-49]. For example, the Men of 1913 Study [47] found that 50-year-old men with DBP $>100 \mathrm{mmHg}$ had significantly lower plasma volume at rest and during and after exercise than men with DBP $<100 \mathrm{mmHg}$. Such differences, however, are not due to loss of extracellular water. Hypertensive and normotensive individuals do not have different amounts of extracellular fluid but rather have an altered distribution of the components of extracellular fluid. In other words, the ratio of intravascular fluid to interstitial fluid is lower in hypertensive than in normotensive individuals [50, 51]. Given that the total amount of extracellular fluid is not different between hypertensive and normotensive individuals, the reduction in this ratio cannot be expected to result from greater renal filtration and excretion of fluid. Instead plasma is displaced from the intravascular to the interstitial space [51]. Furthermore, men with severe [52] and early borderline [53] essential hypertension have a stable red cell mass, indicating that the increased hematocrit among those with essential hypertension is likely due to a contracted plasma volume. However, one must bear in mind that the direction of causality between hypertension and hemoconcentration state cannot be determined on the basis of such observational studies. Altogether, contracted plasma volume and elevated hematocrit suggest that essential hypertension may confer a chronic hemoconcentration state. Given that hematocrit and plasma volume are related to CHD and hypertension and that psychological stress has long been purported to be involved in heart disease, it is not surprising that hemoconcentration effects have been studied during periods of stress. 
A large literature in blood rheology describes the process by which blood flowing through the branches, bifurcations, and curvature of the coronary arteries can lead to stable and unstable atherosclerotic plaques and damage to the endothelium of blood vessels. Researchers applying principles of fluid dynamics to blood flow within arteries have identified that, with increased cardiac output, the intensity of both low- and high-pressure areas on certain parts of the artery surface also increases such that, at predictable areas of intensified low pressure, endothelial cells may lift from the intima, sometimes resulting in shearing endothelial cells from the vessel wall (see Figs. 2 and 3). The force created is a tensile force, in effect a suction action, stimulating the intima to proliferate and to actually become an atherosclerotic plaque. Consequently, damage to the endothelial cells in the low-pressure sites, or eddies, exposes the underlying tunica media, therefore producing intense vascular inflammation, progressive lipid accumulation, and formation and expansion of a necrotic core [54-57]. Interestingly, epidemiological research has shown that the increase in blood viscosity and volume is associated with various types of cardiovascular disease and may prove to be an important link between psychological stress and heart disease in future research. Blood and plasma viscosity and flow rate play a major role in facilitating the low pressure at these sites $[56,58]$. Thus, it is conceivable that stress-mediated increases in blood viscosity could further decrease the pressure at the bifurcations, branches, and curvature of the coronary arteries and increase the exposure time of hemoconcentrated atherogenic substances (i.e., lipids, platelets, and macrophages) to the atherosclerotic lesion. Furthermore, increased blood viscosity is related in part to elevated hematocrit and higher fibrinogen concentrations also due to hemoconcentration effects.

Hemoconcentration and Psychological Stress

Physiologists in several early studies examining hemoconcentration effects subjected volunteers to various physical

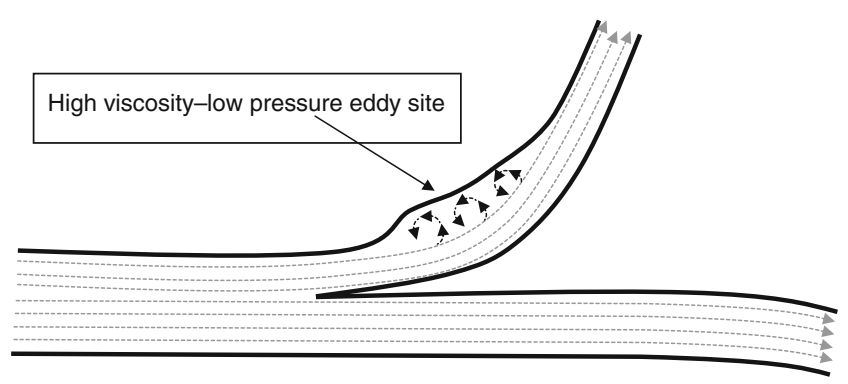

Fig. 2 Flow patterns found at artery bifurcations where blood flow is low and blood viscosity is very high

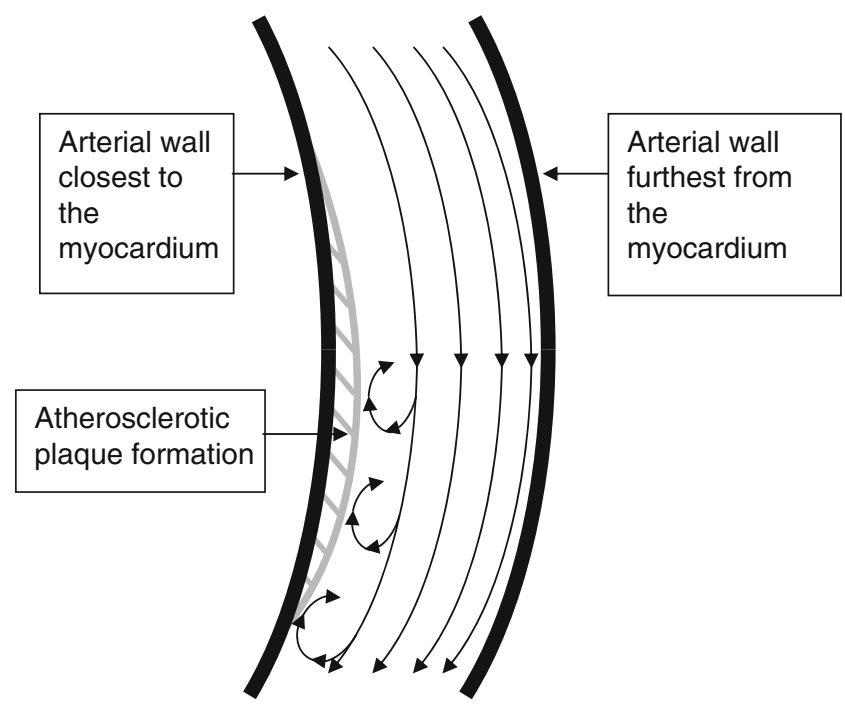

Fig. 3 Flow patterns found along the coronary arteries that follow the curved contour of the heart. Note that vessel wall shear stress and blood flow are lowest and viscosity is highest along the inner arterial wall closest to the heart

stressors such as heat exposure [38, 59, 60], exercise [60], altitude change [36, 61], prolonged bed rest [62], water immersion [63], and head tilt [64]. Plasma volume decreased relative to baseline across all of these stressors. As such, these studies set the stage for the study of hemoconcentration effects resulting from acute psychological stressors as well as physiological challenges such as posture change. Though orthostatic stress results in hemoconcentration and hemostasis changes, the focus of this review is on acute psychological stress. However, orthostatic challenge is important in its own right and has recently been reviewed [65].

Laboratory-induced psychological stress reliably increases the various indices of hemoconcentration (i.e., hematocrit, hemoglobin, blood viscosity, and total plasma protein concentration), presumably due to a reduction of plasma volume. During acute mental stress, the concentration of large molecules (i.e., $>69 \mathrm{kDa}$ ) changes concurrent with plasma volume shifts. Total plasma proteins, immune cells, lipids, platelets, and many coagulation factors greatly exceed $69 \mathrm{kDa}$ (see Table 1). It is clear that these nondiffusible blood constituents, perhaps with the exception of coagulation factors, become hemoconcentrated during acute mental stress (see Fig. 1). With regard to coagulation factors, it is not entirely clear whether acute mental stress causes enhanced coagulation activation through a greater concentration of the factors through stress-hemoconcentration or through actual activation of the coagulation system. The next section reviews previous work examining plasma volume shifts during stress and mechanisms underlying stresshemoconcentration. 
Table 1 Clotting factors in blood

\begin{tabular}{lll}
\hline Clotting factor & Synonyms & $\begin{array}{l}\text { Molecular weight } \\
(\mathrm{kDa})\end{array}$ \\
\hline $\begin{array}{l}\text { Fibrinogen } \\
\text { Prothrombin }\end{array}$ & Factor I & 340 \\
Tissue factor & Factor II & 71.6 \\
Calcium & Factor III; tissue thromboplastin & 44 \\
Factor V & Factor IV & 40 \\
Factor VII & Proaccelerin; labile factor; Ac-globulin & 330 \\
Factor VIII & Serum prothrombin conversion accelerator; & 50 \\
Factor IX & proconvertin; stable factor & 330 \\
Factor X & Antihemophilic factor; antihemophilic globulin; & 57 \\
Factor XI & antihemophilic factor A & 57 \\
Factor XII & flasma thromboplastin component; Christmas & 58.8 \\
Factor XIII & Stuart factor; Stuart-Prower factor & 143 \\
High molecular weight & Plasma thromboplastin antecedent; antihemophilic & 78 \\
kininogen & factor C & 320 \\
\hline
\end{tabular}

Stress-Induced Changes in Indices of Hemoconcentration

Changes in various indices of hemoconcentration have been examined after subjecting participants to acute psychological stress. For instance, Jern and colleagues [66] investigated the hematological and cardiovascular effects of exposure to $10 \mathrm{~min}$ of mental arithmetic and subsequent recovery in healthy young males. Along with increases in heart rate, SBP, and DBP, significant increases in hematocrit and hemoglobin relative to a pre-stress baseline period were observed during the mental arithmetic task. The mean increases in hematocrit and hemoglobin were $0.8 \%$ and $3 \mathrm{~g} /$ 1 , respectively. Moreover, both hematocrit and hemoglobin changes in response to mental arithmetic were significantly correlated with heart rate change. However, the correlations between DBP and SBP with hematocrit and hemoglobin were not significant. In an extension of this study, Jern, Jern, and Wadenvik [67] examined the basal hematological levels in young type A and type B males and females and the effects of a 10-min mental arithmetic task on hematological and cardiovascular measures. Type A individuals had significantly higher basal hematocrit (43.8\% vs. $42.1 \%$ ) and hemoglobin levels (150 vs. $147 \mathrm{~g} / \mathrm{l})$ than type B individuals. Hematocrit and hemoglobin increased significantly during the stressor with magnitudes similar to that reported by Jern et al. [66], but no type A/B differences were observed in the magnitude of change. In both of these studies, hematocrit and hemoglobin returned to baseline levels after the mental arithmetic activity during a 10-min recovery period. This quick return to baseline levels implies that the hemoconcentration was due to reversible shifts in plasma volume.
Similar findings have been observed with other stressors and with additional measures of hemoconcentration. For example, compared to individuals resting quietly, the total plasma protein concentration increased significantly in individuals completing the Stroop Color-Word Interference Test and orthostatic challenge, but correcting for plasma volume changes rendered these effects non-significant [68]. Furthermore, an index of cardiovascular "reactivity" (residualized heart rate and blood pressure change scores were standardized and summed) was positively correlated with stress-induced changes in total cholesterol level and hematocrit [67]. In a similar study [32], plasma volume, plasma viscosity, total plasma proteins, blood pressure, and heart rate were assessed in healthy, young men during a 30min rest period and a 5-min speech stressor. Plasma volume decreased significantly during the stressor, which corresponded to an increase in plasma viscosity and in total plasma protein concentration. In addition, a change in plasma volume from baseline to stress had a significant, negative correlation with changes in heart rate and SBP. Similar relationships between hemoconcentration and hemodynamic measures were reported by Veldhuijzen van Zanten and associates [69-71]. On the other hand, Bacon and colleagues [28] found no relationship between blood pressure changes and stress-induced hemoconcentration in patients with CHD and suggested that this may be due to the likely relatively poorer endothelial function of diseased patients. Altogether, with the exception of a few studies $[28,66,67]$, these lines of evidence suggest that, in healthy individuals, increased hydrostatic pressure from sympatheticinduced cardiovascular responses to stress is responsible for the movement of fluid into extravascular spaces and the 
consequent concentration of non-diffusible blood components $[32,68]$.

The reason why Jern and colleagues $[66,67]$ did not find a relationship between blood pressure changes and hematocrit changes is not entirely clear, although low power due to small sample sizes is one possibility. Alternatively, changes in various substances known to alter vascular permeability (e.g., atrial natriuretic peptide, histamine, norepinephrine, and tryptase) could provide another avenue for stress-hemoconcentration and perhaps could mediate stress-hemoconcentration [70]. However, no relationship was found when examining changes in tryptase as a possible mechanism of stress-hemoconcentration [70]. Nevertheless, other substances that regulate vascular permeability may play a role in stress-hemoconcentration and should be examined in the future.

Although these studies strongly suggest that hemoconcentration occurs relatively quickly during acute stress, they did not address how long it takes for a hemoconcentration state to return to normal (i.e., recovery time). Patterson and colleagues [40] reported the hemoconcentration effects for total plasma proteins among healthy males and females completing a 10-min stressful serial subtraction task with harassment compared to control individuals completing a benign reading task. Calculated plasma volume and mean arterial pressure (MAP) were measured every 2 min during the mental arithmetic task and every 3 min during the 30 min recovery period. The percent change in plasma volume relative to baseline was negatively correlated with MAP across the mental arithmetic task and recovery period. Moreover, the percent change in plasma volume remained depressed and MAP remained elevated during the first $9 \mathrm{~min}$ of the recovery period, but both returned to baseline levels after $12 \mathrm{~min}$ of recovery. It was concluded that stressinduced changes in plasma volume and blood pressure return to normal within $12 \mathrm{~min}$ and these changes coincide during the stress task and recovery period. Thus, further support was provided for the notion that blood pressure elevations are the driving force behind plasma volume losses during stress and subsequent hemoconcentration of non-diffusable blood components. However, as Patterson and associates [40] acknowledged, increased renal function and diuresis following stress could account for plasma volume losses. Along the same lines, Muldoon and colleagues [72] reported that, in healthy male participants, plasma volume remained lower than baseline levels after a 30-min recovery period following mental arithmetic and a Stroop task; thus, it was suggested that increased renal filtration could be responsible for prolonged plasma volume losses. However, blood pressure and plasma volume were only measured at the end of the recovery period, so one cannot rule out the possibility that they corresponded inversely throughout the recovery period. It is also possible that plasma volume losses are driven by a combination of increased blood pressure, increased renal filtration, and changes in substances regulating vascular permeability.

de Boer and colleagues [9, 29, 73] further examined the time course and mechanisms of hemoconcentration in response to mental stress as well as the relationships between hematological and cardiovascular variables. In the first study [73], male participants completed a 4-min paced auditory serial addition test and were led to believe that their performance would be analyzed for body and facial composure during the task. Hematocrit increased gradually during the first 3 min of mental stress, plateauing in the fourth minute. Hematocrit was at its highest level in the first minute of recovery and steadily decreased back to baseline levels within 16 min of the recovery period, which is somewhat similar to $12 \mathrm{~min}$ following a 10-min math stressor in the Patterson et al. [40] study. Therefore, the recovery time may be relatively independent of the length of the stress task, at least in the case of math stressors (i.e., serial subtraction and paced auditory serial addition test) lasting up to $10 \mathrm{~min}$. However, it is possible that recovery slows down with stressors of longer duration or of different types. Such a possibility is supported by the findings of a study in which hematocrit failed to return to baseline levels 30 min after a 20-min combined Stroop-mental arithmetic task [72]. Furthermore, within-subjects correlations between hemodynamic variables and hematocrit from baseline through recovery were significant [73], which is consistent with between-subjects observations seen in previous studies [8, 32], providing more support for the notion that blood pressure changes underlie hemoconcentration during stress. Alternatively, subsequent studies [9, 29] suggest that hematocrit recovery after the termination of a stressor may be independent of blood pressure changes and may rely more on intravascular colloid osmotic pressure to draw plasma back into the vascular compartment, therefore suggesting that greater colloid osmotic pressure produces quicker post-stress plasma volume recovery.

The aforementioned studies have all included normotensive individuals as participants, but a number of studies have assessed hemoconcentration and hemodynamic stress responses in hypertensive patients. For instance, Kitahara and colleagues [74] studied men and women with mild hypertension who underwent a 10-min period of speech and mental arithmetic followed by a 60-min recovery period. The mental stress period resulted in a significant increase of hematocrit $(0.7 \%)$ and hemoglobin $(2 \mathrm{~g} / 1)$, which returned to baseline levels during the recovery period. Parallel increases in blood pressure and heart rate were observed during the stressor, with significant positive correlations between hematocrit change and both SBP change and heart 
rate change. Sakamoto, Imataka, Nishimura, and Fujii [75] conducted a very similar study utilizing the same stressor as well as isometric handgrip exercise and found comparable increases in hematocrit $(0.5 \%$ for both tasks) and blood pressure.

Stress-hemoconcentration effects reliably occur during a variety of mental stressors, whether it is observed as changes in hematocrit, hemoglobin, total plasma protein concentration, or plasma volume. Stress-hemoconcentration is observed in men and women, normotensive and hypertensive individuals, and people of different age groups. A large amount of evidence indicates that tasks producing sympathetic nervous system activation result in the largest increases in hematocrit and hemoglobin and that these changes are likely produced by increases in blood pressure and heart rate.

As previously discussed, blood viscosity increases when stress-hemoconcentration occurs. Psychologically stressful events could precipitate acute coronary syndromes through this mechanism. The disruption of normal blood rheology is probably most important in areas of the vasculature where a vulnerable plaque is already present or in areas of low blood flow [7]. Where a plaque is already present, the plaque itself increases local shear stress and viscosity by reducing the vessel's diameter. An even greater increase in viscosity could precipitate plaque fissuring and thrombus formation [76]. In areas of low blood flow, increased viscosity could further decrease pressure and increase the amount of time that concentrated blood components (e.g., lipids, platelets, clotting factors) have contact with the endothelium. In turn, endothelial cells could be lifted from the intima, affording a greater opportunity for the aggregation of platelets and subsequent thrombus formation [7, 76].

In addition to elevated blood viscosity, stresshemoconcentration is accompanied by hypercoagulation [18]. Moreover, hypercoagulation may be a mechanism of acute coronary syndromes initiated by acute psychological stress $[10,11]$. Therefore, the remainder of this review describes hemostasis physiology and links between hemostasis and heart disease as well as provides an update on the research examining coagulation and platelet changes during acute stress. Finally, links between coagulation and stresshemoconcentration are discussed.

\section{Hemostasis}

Hemostasis is a critical defense mechanism against bleeding whereby blood loss is prevented after a vessel is damaged [20]. Theorists have long associated psychological stress with accelerated hemostasis and thickening of the blood. Given that hemostasis factors are of primary importance to this review article, hemostasis will be described in detail. Particular emphasis is placed on coagulation factors, leading to the central question addressed here-whether the apparent increase in coagulation activity during acute psychological stress is due to the actual activation of the coagulation system or as a result of hemoconcentration, or a combination of both.

\section{Hemostasis Physiology}

Hemostasis is a complex process that stops bleeding, often changing blood from a fluid to solid state. The process of hemostasis is achieved by three fundamental processes vascular spasm, platelet plugging, and coagulation [20, 77]. Figure 4 provides a schematized view of hemostasis.

\section{Vascular Spasm}

First, a vascular spasm occurs to minimize the immediate loss of blood. The vessel walls contract immediately after a blood vessel suffers a trauma to minimize the amount of blood leaving the vessel. The vascular spasm can last for minutes to hours, during which time the other two mechanisms for halting blood loss occur (i.e., platelet plugging and blood coagulation).

\section{Platelets}

Platelets are minute, round or oval anuclear cells that serve several hemostatic functions. They are activated either when stimulated by various agonists or when contacting a foreign surface or the subendothelial collagen of a damaged vessel wall. Once activated, they have granules that move to the platelet surface and release their contents into the plasma. Two types of granules are of primary concern to hemostasis: alpha granules and dense bodies. The alpha granules contain many important substances involved in thrombosis and atherosclerosis, including fibrinogen, platelet factor 4 (PF4), beta-thromboglobulin (BTG), Factor V, Factor VIII, von Willebrand factor, and platelet-derived growth factor [78, 79]. Substances released from platelet granules, especially thromboxane $\mathrm{B}_{2}$ (a metabolite of thromboxane $\mathrm{A}_{2}$ ), PF4, and BTG, are often measured as markers of platelet activation $[5,6,80]$. Dense bodies hold adenosine diphosphate, calcium ions, and thromboxane $A_{2}$, all of which activate other platelets.

Once activated, the platelets undergo drastic changes to carry out the following functions: (1) formation of a platelet plug to occlude sites of vascular damage, (2) provide a surface for the configuration and activity of coagulation proteins, (3) serve as the nucleus around which a fibrin clot forms, and (4) secrete various factors involved in vascular repair [78]. When activated, platelets swell, assume irregular forms, become sticky, and activate other platelets. 
Fig. 4 Overview of hemostasis

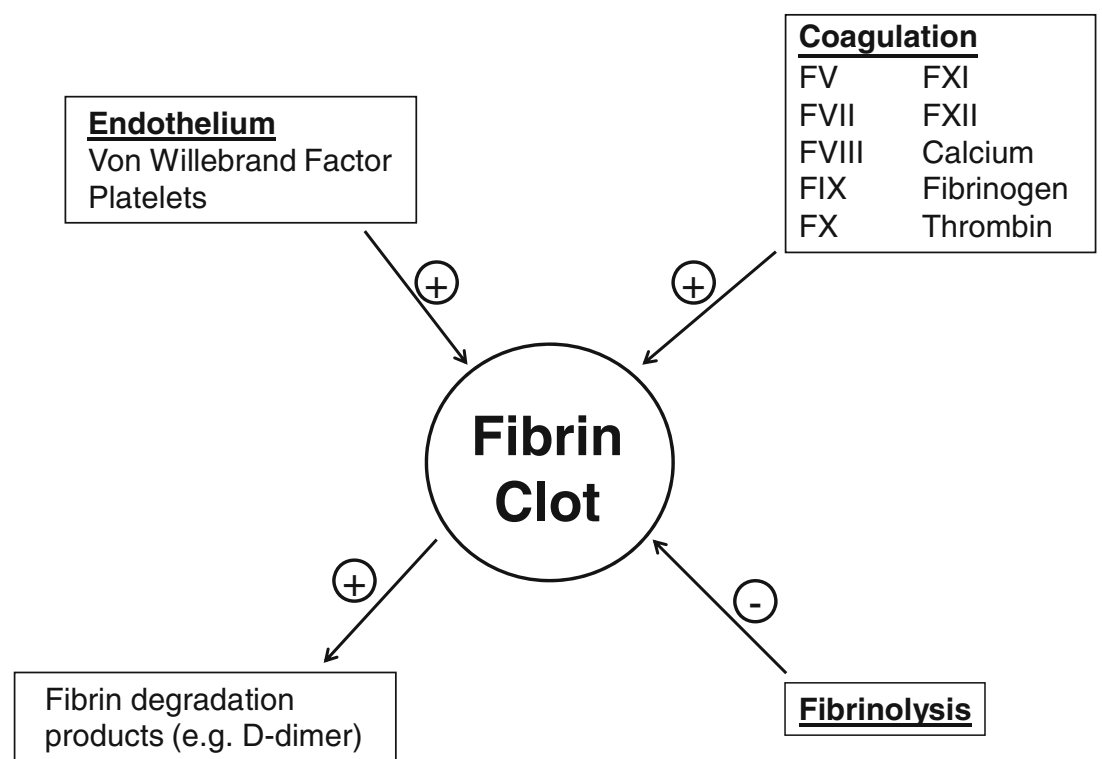

The stickiness of platelets causes them to adhere to each other. This process continues, attracting more and more platelets to the newly forming platelet plug. At first, the platelet plug is loose, but it sufficiently blocks blood loss if damage to the vascular wall is minor. If a rupture is very small, it is often sealed only by a platelet plug. Minute ruptures occur in very small blood vessels hundreds of times daily. Thus, the formation of the platelet plug is extremely important for closing these minute ruptures. If the rupture is severe, however, then platelets stimulate blood coagulation, the third step in hemostasis, through the release of activator substances [20,77]. Another response of platelet activation is the expression of receptors for coagulation factors [79]. Coagulation factors, in turn, bind to and stimulate platelets in a positive feedback fashion to form the final hemostatic plug [78].

\section{Blood Coagulation}

Blood coagulation is the formation of a blood clot in a damaged vessel or through inappropriate activation such as during thrombus development. More than 50 substances affect coagulation. Whether or not blood will coagulate depends on the balance between anticoagulants and procoagulants. In normal states, anticoagulants predominate and clots do not develop [81]. However, after a vessel ruptures, procoagulants become "activated" and override anticoagulants, resulting in the development of a blood clot. Rapid clotting in such situations or during pain or psychological stress is adaptive because it prevents fatal bleeding from occurring [82].

Coagulation takes place in three essential steps: formation of prothrombin activator, conversion of prothrombin to thrombin, and formation of a clot through the conversion of fibrinogen to fibrin [20]. These steps were described by two independent laboratories as a cascade [83] and a waterfall [84] in which the activation of one clotting factor leads to the activation of another, culminating in a burst of thrombin generation that catalyzes the conversion of fibrinogen to fibrin. Although these two groups labeled coagulation differently, they both described the same basic model. Eventually, the waterfall label was abandoned but the cascade term has persisted. In this model, the clotting factors are proenzymes (i.e., inactive precursors of enzymes) that are available to be converted to active enzymes. This model further suggests that clotting can be initiated by either the extrinsic or intrinsic pathway, each of which ultimately leads to a common pathway. The extrinsic and intrinsic pathways correspond to the first step of coagulation - the formation of prothrombin activator. At the end of this step, the two pathways merge into a common pathway. Once the prothrombin activator is formed, it converts prothrombin to thrombin. Thrombin must then be present to convert fibrinogen to fibrin so that a clot can form [20]. The extrinsic pathway, intrinsic pathway, and common pathway are described in detail (Fig. 5).

Extrinsic Pathway The extrinsic pathway is initiated by tissue damage, which triggers the release of a complex of factors (i.e., tissue factor) released into the blood by damaged tissue. Two important parts of this complex are phospholipids from the cell membranes of the tissues and a lipoprotein complex that contains a critical enzyme. Once tissue factor is released, the lipoprotein complex acts enzymatically on Factor VII (FVII), resulting in activated Factor VII (FVIIa). FVIIa, in the presence of calcium, acts on Factor X (FX) to form FXa. FXa combines with the phospholipids of tissue factor and with FVa to form 


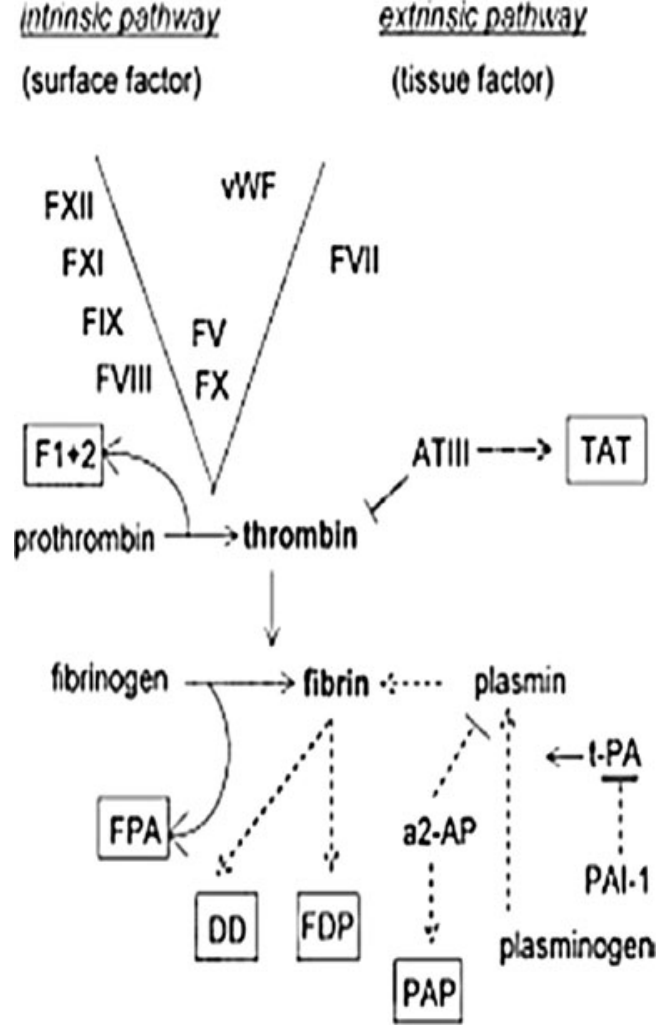

Fig. 5 The scheme depicts coagulation pathways in solid lines and fibrinolysis pathways in dashed lines. Anticoagulant steps are drawn in dash-dotted lines. Roman numerals indicate coagulation factors. The prethrombotic markers of a hypercoagulable state are depicted in boxes. a2-AP a2-antiplasmin, $A T$ III 5 antithrombin III, $D D$ fibrin Ddimer, $F 112$ prothrombin fragments 112, FDP 5 fibrinogen/fibrin degradation products, FPA fibrinopeptide A, $P A P$ plasmin-a2antiplasmin complex, $t-P A$ tissue plasminogen activator, $P A I-1$ type 1 plasminogen activator inhibitor, $v W F$ von Willebrand factor, TAT thrombin-antithrombin III complex. The symbol " $\perp$ " indicates the inhibition steps of thrombin, plasmin, and t-PA. Adapted with permission from "Effects of psychological stress and psychiatric disorders on blood coagulation: A biobehavioral pathway to coronary artery disease?" by R. von Känel et al. [10], p. 32 (copyright 2001 by Wolters Kluwer Health)

prothrombin activator $[20,77,81]$. Clotting via the extrinsic pathway is fast, taking as little as $15 \mathrm{~s}$ [81]. Table 1 contains a list of clotting factors, their synonyms and molecular weights.

Intrinsic Pathway The intrinsic pathway is so named because all of its components are present in the blood. The intrinsic pathway is most likely implicated in CHD because CHD develops inside the vasculature. It is initiated by blood contact with a damaged interior vessel surface, which activates platelets. When platelets become activated, they release phospholipids and their membranes become negatively charged. Factor XII (FXII) is a plasma protein that becomes activated (FXIIa) when coming into contact with a negatively charged surface such as a glass test tube or the membrane of an activated platelet. Subsequently, FXIIa acts on FXI, resulting in FXIa. FXIa acts enzymatically on FIX, resulting in FIXa. FIXa acts in concert with FVIIIa to activate FX, resulting in FXa. FXa combines immediately with platelet phospholipids and FVa to form prothrombin activator [20, 77, 81]. Clotting via the intrinsic pathway is much slower than via the extrinsic pathway and takes 1 to $6 \min [20]$.

Final Common Pathway After prothrombin activator is formed by the extrinsic or intrinsic pathway, it catalyzes the conversion of prothrombin to thrombin. In addition, platelets play an important role in the conversion of prothrombin to thrombin. Much prothrombin first attaches to prothrombin receptors on platelets bound to a damaged tissue. This binding, in turn, accelerates the formation of thrombin from prothrombin at the exact location where a clot is needed. Subsequently, thrombin has a number of important physiological functions. First, it activates platelets to help in the formation of a platelet plug. Second, it acts in a positive feedback fashion on the coagulation system by increasing the activation of FV and FVIII. Finally, it is essential for the conversion of fibrinogen to fibrin, the last step of the coagulation cascade [20].

Within $10-15 \mathrm{~s}$ of its formation, thrombin acts enzymatically to convert fibrinogen to fibrin monomers. Fibrin monomers have the automatic capability of joining together to form long fibrin fibers. These fibrin fibers then enmesh platelets, blood cells, and plasma to form a clot. Additionally, fibrin fibers adhere to damaged surfaces of blood vessels. Thus, the blood clot adheres to any vascular opening, thereby preventing blood loss [20].

\section{Fibrinolysis}

Once a clot has started to develop, it normally expands into the surrounding blood within minutes [20]. The clot initiates a vicious cycle (i.e., positive feedback) to promote more clotting by stimulating platelets as well as parts of the clotting cascade itself. The blood clot continues to grow until something stops its growth. Termination of clot growth is accomplished by the plasma protein system known as the fibrinolytic system. The process of fibrinolysis works to prevent the vasculature from becoming one uncontrolled, continuous clot. The main function of the fibrinolytic system is the removal of minute clots from the millions of tiny peripheral vessels that would eventually become occluded were there no way to break down and clear them. However, the fibrinolytic system also clears larger clots that occur with severe vessel damage, such as those occurring from lacerations [20, 85]. In the long run, the components of the fibrinolytic system interact with the coagulation system to keep the blood from becoming either too thick or too thin. 


\section{Other Factors Involved in Hemostasis}

Numerous other physiological factors are involved in hemostasis. Plasma D-dimer is a molecular marker of hemostatic activation [85] whose level reflects fibrin turnover both from intravascular fibrin formation and from consequent fibrinolysis. As opposed to other hemostatic markers, D-dimer is more easily detected in plasma because of its comparatively longer half-life and because it is a marker of activation of both the coagulation and fibrinolysis systems [86]. Thus, it is likely a reliable indicator of in vivo activation of the hemostatic system [87].

von Willebrand Factor (vWF) is a very large molecule released from stimulated or damaged endothelial cells. Thus, the plasma level of vWF indicates endothelial cell dysfunction. Once released into the circulation, vWF plays an essential role in hemostasis by triggering platelet adhesion to places of vascular injury in areas of high shear stress (e.g., in arterioles and microcirculation) and the aggregation of platelets to each other. Furthermore, vWF indirectly influences the coagulation cascade by acting as the carrier protein for FVIII in the plasma $[78,88]$.

\section{Cell-Based Model of Hemostasis}

It should be noted that many researchers have adopted a cell-based model of coagulation in favor of the cascade model because the coagulation model has shortcomings as a model of the hemostatic process in vivo [89-91]. In this model, procoagulant forces are restricted to the site of vessel damage rather than extending throughout the vasculature. Such control of coagulation is achieved by localizing the procoagulant reactions at the site of injury on specific cell surfaces, particularly platelets and tissue factorbearing cells. These two types of cell interact to either inhibit or accelerate clotting [89]. However, the existing clotting assays used to assess tissue factor activity lack sensitivity and specificity [92]. Moreover, an examination of acute clotting changes in vivo such as those occurring during acute psychological stress is challenging. Therefore, research has been restricted to changes measured in vitro within the scope of the cascade model.

\section{Hemostasis and Cardiovascular Disease}

A very large number of studies have examined the links between various aspects of hemostasis to cardiovascular disease. A detailed examination of this research is beyond the scope of this review. Therefore, this section only provides a brief overview of research examining the relationships between platelets and coagulation factors and CHD and hypertension.
Platelets and Coronary Heart Disease

Platelets play an important role in the development of CHD. Their importance is emphasized by the effectiveness of aspirin, a platelet aggregation inhibitor, in reducing the incidence of myocardial infarction [93]. Regarding pathophysiology, platelet-derived growth factor causes smooth muscle cells to grow and migrate into the intima of arteries. Smooth muscle is a primary component of mature atherosclerotic plaques [94]. Furthermore, the platelets themselves bind to foam cells that are exposed when the endothelium becomes damaged in the initial stages of plaque formation. When platelets adhere to exposed endothelium at the site of a lesion, they increase the size of the lesion and capture leukocytes on the lesion surface, forming platelet-leukocyte aggregates (PLAs; [95]). Plateletleukocyte binding additionally promotes several processes involved in inflammation and thrombosis, such as fibrin formation and deposition within a developing thrombus [96]. These processes occur at the beginning of atherosclerotic development, but platelet function is also intimately involved in the later stages of $\mathrm{CHD}$, such as in acute coronary syndromes. At points of increased wall shear stress, plaques are more likely to fissure and rupture. It is at these sites to which platelets adhere, followed by subsequent platelet activation. Once activated, platelets release various substances involved in vessel occlusion and play a central role in the formation of arterial thrombi. After adhering to a site of rupture, they release thrombin and platelet agonists, such as adenosine diphosphate, serotonin, and thromboxane $\mathrm{A}_{2}$, leading to further platelet recruitment, activation, and aggregation [96].

Further showing the importance of platelets in CHD are epidemiologic studies showing the increased levels of platelet markers (i.e., BTG and PF4) and PLAs in patients with acute coronary syndromes, unstable angina, and stable CHD (for reviews, see $[5,92]$ ). In the vast majority of studies, platelet markers and PLAs have a positive relationship with CHD. Moreover, patients with stable CHD have elevated levels of circulating activated platelets and have platelets that are more reactive to platelet agonists compared to healthy controls [97].

\section{Blood Coagulation and Coronary Heart Disease}

Many coagulation factors have been associated with hypertension and CHD. Of these, fibrinogen and D-dimer are probably the strongest risk markers, although other hemostasis variables (e.g., FVII, FVIII, and vWF) have independently predicted CHD in some [98-102] but not in all studies [12, 103, 104]. Hypercoagulability likely spurs the chronic development of CHD by providing an environment for gradual deposition of fibrin within atherosclerotic 
plaques [105]. Notwithstanding the long-term unfavorable effects on the vasculature, a procoagulant environment also plays a central role in CHD by speeding thrombus enlargement after plaque disruption [106]. Thus, if periods of acute psychological stress stimulate hypercoagulability, then it is plausible that such stressful events could precipitate the initiation of CHD [10].

\section{Hemostasis and Acute Psychological Stress}

\section{Platelets and Stress}

It has long been known that catecholamines (i.e., norepinephrine and epinephrine) are strong stimuli for platelet activation in vitro [107-109] and that platelets contain alpha $_{2}$-adrenergic receptors [110]. Individuals with various psychological disorders, including general anxiety disorder, panic disorder, and posttraumatic stress disorder, have fewer platelet alpha $a_{2}$-adrenergic receptors available for binding (i.e., catecholamines are already bound to a large number of receptors), which is consistent with the greater catecholamine concentrations also seen in these conditions [111]. Emotional stress stimulates the sympathetic nervous system, which in turn causes the release of catecholamines $[111,112]$ that have the potential to activate platelets.

Table 2 in the "Electronic Supplementary Material" summarizes a large body of research, which suggests that acute psychological stress is related to changes in platelet activity in individuals with and without cardiovascular disease. Platelet aggregability appears to increase immediately after acute psychological stress [113-116]. Additionally, many studies report increases in the levels of the platelet activation markers circulating platelet factor 4 (PF4) and beta-thromboglobulin (BTG) among healthy individuals [6, 116-121] and among individuals with essential hypertension [122] and with angina pectoris [123]. However, not all studies have reported significant changes in platelet aggregability [124-126] and platelet activation markers $[123,127,128]$ in response to acute stress. For example, Wallén and colleagues [123] reported that acute stress did not elicit elevations in these platelet activation markers in elderly healthy volunteers. They speculated that the balance between platelet activation and inhibiting systems during tasks that elicit acute stress may be different in elderly than in younger individuals. Alternatively, there may be more variation in artefactual platelet activation resulting from older methods of assessing platelet function [129].

Although platelet activation markers generally increase during acute psychological stress in both groups, hypertensive individuals have larger or prolonged responses of these markers than healthy, normotensive individuals. For instance, platelet activation following epinephrine infusion is greater in hypertensive individuals than in normotensive individuals [130]. Similarly, Tomoda and colleagues [122] reported that the BTG response is dependent on the hypertensive status. Normotensive individuals did not have BTG changes during a mental arithmetic stressor, whereas individuals with World Health Organization [131] stage 1 (SBP 140-159 or DBP 90-99) and stage 2 (SBP 160-179 or DBP 100-109) hypertension had significant BTG increases. Individuals with stage 1 hypertension had greater increases during mental arithmetic than individuals with stage 2 hypertension, which is most likely due to platelet function already being enhanced in the resting period among those with stage 2 . The temporary increase in platelet function during stress in the early phase of hypertension (i.e., stage 1) could bring about a perpetual enhancement of platelet function in the more advanced phase of hypertension (i.e., stage 2; 122). Furthermore, epinephrine infusion in vivo may cause greater platelet activation and aggregation, and platelets from hypertensive men appear to be even more responsive to epinephrine compared to platelets from normotensive men (for a review, see [132]).

The findings are less consistent when examining stressinduced changes in platelet activation markers in CHD patients. Bacon and colleagues [133] reported that PF4 did not change following the paced auditory serial addition test, similar to Wallén et al. [123]. In another study [120], BTG levels increased significantly following a structured interview and speech task in the control group, but not in postinfarction patients. Similarly, Reid et al. [128] found no change in BTG in CHD patients following a stressor protocol that included mental arithmetic and anger recall. Conversely, Wallén et al. [123] found that BTG levels increased significantly following a Stroop task among angina patients. It is unclear why these dissimilar results occurred, but the differences in stressor intensity or disease severity may have played a role.

A few studies have assessed PLA responses to acute stress. However, the results from such studies are more consistent than those of studies examining stress-induced changes in platelet activation markers. Moreover, the measurement of circulating PLAs via flow cytometry may provide a more sensitive marker of in vivo platelet activation [96]. One study [134] examined PLA responses to a color/word interference task and mirror tracing task in healthy, middle-aged men. Total circulating PLAs, as well as three sub-populations of aggregates (platelet-monocyte, platelet-neutrophil, and platelet-lymphocyte aggregates), increased significantly after the behavioral stressors. However, the peak increase in PLA levels was observed $30 \mathrm{~min}$ post-stress as opposed to immediately after the tasks, indicating that PLA responses are delayed in comparison to blood pressure and heart rate reactivity. Nevertheless, 
total PLAs and platelet-monocyte aggregates were positively related to SBP changes immediately after stress, implicating the sympathetic nervous system, at least in part, in the PLA response to acute stress [134]. Two studies have been published that examined stress-induced PLA changes in patients with CHD [17, 128]. Both studies reported that PLAs increased after acute stressors. However, Reid et al. did not include a control group and did not examine recovery. On the other hand, Strike and colleagues compared the PLA response to a color/word interference task and mirror tracing in male patients with established CHD to the PLA response in healthy, age-matched controls. Although there were no differences between the two groups in PLAs at baseline and the increases in PLAs during stress, PLAs remained elevated for an extended period of time (75 min) in the patients with CHD but, similar to Steptoe et al. [134], PLAs returned to baseline levels in the controls. Therefore, the prolonged elevation of PLAs provides one mechanism through which patients with CHD may be vulnerable to acute coronary syndromes in the 1-2 $\mathrm{h}$ immediately after acute stress. Still, one must use caution in interpreting the results from observational studies using CHD patients and non-patients because it is impossible to tease apart whether changes in response to acute stress in patients precede and cause their disease state or are a consequence of it.

A major limitation in the vast majority of platelet stress reactivity studies is that adjustments for stresshemoconcentration have generally not been conducted. One exception [121] suggests that the effects of acute stress on PF4 and BTG levels are independent of hemoconcentration. That is, elevations in PF4 and BTG survived mathematical correction for plasma volume shifts. Rather, changes in platelet activation are most likely related to increased catecholamine secretion [119, 121]. Along these lines, the adrenergic binding sites on platelets undergo changes and may become desensitized or have increased density following acute psychological stress [135, 136], suggesting catecholamine surge and, subsequently, greater platelet activation. Moreover, although the overall levels of PLAs and platelet-monocyte aggregates decreased across two sessions at 4 weeks apart, the platelet response to acute psychological stress appears to be resistant to habituation $[137,138]$. That is, the platelet activation response to acute stress did not decrease over 4 weeks. Altogether, platelets seem to become more active during psychological stress and this response does not habituate. Over time, elevated platelet activation resulting from acute stress could promote processes involved in inflammation and thrombosis, providing one possible mechanism through which stress may be linked to cardiovascular disease.

Activated platelets release activator substances that initiate coagulation activity. Once the platelets become activated, they also express receptors for coagulation factors. Subsequently, coagulation factors bind to and further stimulate platelets. Thus, platelet activation initiates but also perpetuates clotting activity [20, 77-79]. If psychological stress activates platelets, platelets may, in turn, stimulate blood coagulation. The following section reviews coagulation and its relationship to acute psychological stress.

\section{Blood Coagulation and Acute Stress}

As early as the 1910s, Cannon and Mendenhall [139] showed that blood coagulation was accelerated in cats in "fight-flight" circumstances, such as pain and emotional excitement. Such conditions also increase adrenal secretion. In addition, Cannon and Gray [140] showed that injecting adrenalin (i.e., epinephrine) shortened clotting time. Furthermore, Cannon and Mendenhall [82] reported that adrenalin secretion from the adrenal glands as occurs with splanchnic stimulation accelerated clotting. Taken together, these early findings indicate that sympathetic activity accelerates coagulation. Rapid clotting during pain or emotional excitement is adaptive, defending the organism against fatal bleeding that could occur during an injury [82].

Cannon's work set the stage for the next century of research that examined the effects of emotion, stress, and anxiety on coagulation as well as fibrinolysis. von Känel and colleagues [10] reviewed this work and concluded that both coagulation and fibrinolysis activities increase during acute psychological stress but that coagulation increases to a greater extent than fibrinolysis, resulting in net hypercoagulability. Moreover, a recent review by Thrall and colleagues [11] reported that the findings of studies examining the effects of acute psychological stress on fibrinolysis have been inconclusive. For example, studies have reported increases, no change, and decreases in tissuetype plasminogen activator (t-PA), the molecule accountable for degrading fibrin into soluble fragments [11]. This inconsistency might partially be explained by the fact that studies have variously investigated the activity or antigen levels of t-PA [10]. This would be an important distinction because, while the increased levels of t-PA activity mean enhanced fibrinolysis, the elevated t-PA antigen levels reflect reduced fibrinolysis as t-PA antigen indicates the amount of active t-PA that has become inactivated in a complex with plasminogen activator inhibitor-1. However, an extended review of such studies is beyond the scope of this paper. Therefore, only recent studies of the effects of acute stress on coagulation are discussed here.

Investigations of the effects of acute psychological stress on coagulation have generated generally positive findings for markers of the intrinsic and extrinsic coagulation 
pathways as well as markers of the common pathway (see Table 3 in the "Electronic Supplementary Material"). Such findings are observed in healthy individuals and in patients with essential hypertension and CHD. The concentrations or the activity of fibrinogen, FVII, FVIII, FXII [141-146], and D-dimer [146-149] usually increases during acute psychological stress. Increased fibrinogen levels suggest the activation of the common pathway of coagulation. Elevations of FVIII and FXII levels suggest a greater activity of the intrinsic pathway, whereas elevations of FVII levels suggest a greater activity of the extrinsic pathway. Increased D-dimer levels suggest that procoagulant forces prevail over anticoagulant influences, even though coagulation and fibrinolysis are coexistent with acute mental stress [10].

In contrast, some studies have reported equivocal changes in clotting activity resulting from acute psychological stress. For example, fibrinogen concentration has not always increased significantly during the Stroop task [68] and the Trier Social Stress Test (TSST; 144, 150). However, the results from these studies were in the expected direction, and nonsignificance likely occurred due to the low statistical power arising from small sample sizes. Additionally, some studies have not found a statistically significant increase in D-dimer during acute mental stress in men [18, 142, 143, 150] and women [142]. Such discrepancies may be due to the use of different assays. The aforementioned studies [146-149] that reported significant increases in D-dimer used enzyme-linked immunosorbent assays (ELISA), but other studies [18, 143, 150] used a turbidimetric method, which may have poorer sensitivity [151] and agreement [152] than ELISA. However, this does not explain why Steptoe and associates [142] did not find a significant increase in D-dimer with acute stress using ELISA. von Känel and colleagues [146-149] used an ELISA that may be more sensitive to stress-related changes in D-dimer compared to the ELISA used by Steptoe and colleagues

An alternative explanation for mixed D-dimer findings is in the use of different stressors. Steptoe et al. [142] used counterbalanced 5-min Stroop and 5-min mental arithmetic tasks, whereas von Känel et al. [18, 143, 150] used the TSST, an evaluative stressor in which the participants give a speech and perform mental arithmetic in front of an audience [153]. In a comprehensive meta-analysis, Dickerson and Kemeny [154] concluded that the psychosocial stress tasks that have unpredictable and social-evaluative threat components elicit the largest hormonal changes (namely, cortisol) and have the longest recovery times. The TSST is characterized by unpredictability and threat of social evaluation. However, there may not have been a social-evaluative threat element in the Stroop and mental arithmetic tasks in the study conducted by Steptoe et al.
[142]. This argument is based on the presupposition that hormonal changes arising from social-evaluative threat are driving coagulation changes during acute stress. However, during a 148-min stress protocol that included a 30-min baseline period, 13-min TSST, and 105-min recovery period [150], D-dimer stress reactivity and cortisol reactivity were unrelated. The lack of relationship between Ddimer reactivity and cortisol reactivity could be due to the approximate $30-\mathrm{min}$ lag in cortisol response to a stressor, whereas D-dimer tends to increase within minutes of the initiation of a stressor. Thus, cortisol and D-dimer have peaks that are completely out of phase with each other, and reactivity should not be expected to coincide. On the other hand, catecholamine reactivity is related to D-dimer reactivity, especially given that both have stress responses that follow similar time courses. In fact, norepinephrine significantly explained $3.7 \%$ of the variance in D-dimer stress change among healthy men [155]. Altogether, it appears that D-dimer concentrations increase during acute stress when D-dimer is assessed via a sensitive ELISA and the stressor is characterized by unpredictability and socialevaluative threat.

Equivocal findings have also been reported for vWF and measures of clotting time. vWF increased significantly during the Stroop task and mental arithmetic in males [141] but not in females [156]. It is possible that this difference is due to the hormonal differences in females during the different phases of the menstrual cycle, indicating the need to control for phase of the menstrual cycle when examining coagulation responses to acute stress. Prothrombin time (PT) and activated partial thromboplastin time (APTT) are temporal measures of the extrinsic and intrinsic pathways of coagulation, respectively. Of the studies examining coagulation times, two studies have reported no change in APTT during acute psychological stress $[9,150]$ while another reported a shortening of APTT [18]. PT showed no change in one study [143], a shortening trend in another [9], and a significant shortening in yet another [18]. One possible explanation for these incongruous findings is that the most recent study [18] aggregated prothrombotic changes across two stress sessions, while prior studies only examined responses at one stress session. Aggregation across multiple measurements is more likely to yield more robust physiological effects than a single measurement [157].

How acute psychological stress elicits increased coagulation is not fully understood [10, 18]. One possible mechanism is stress-induced catecholamine spillover and altered adrenergic receptor functioning. Consistent with this explanation, the infusion of epinephrine results in the elevation of clotting activity of various coagulation markers. von Känel and Dimsdale [132] reviewed studies examining such effects and found that blood clotting time (assessed by various means) shortened in nine of 11 studies 
and elevations in vWF antigen were observed in seven of seven studies. Moreover, FVIII increased in all 15 studies reviewed and increased significantly in 14 of those studies. The mean peak increase for FVIII was $206 \%$ and was seen on average after $19 \mathrm{~min}$ of infusion. However, in studies measuring the recovery after termination of infusion, some noted that FVIII returned to baseline after $30 \mathrm{~min}$ [158] and $6 \mathrm{~h}$ [159], whereas others showed incomplete recovery after $30 \mathrm{~min}$ [160] and $90 \mathrm{~min} \mathrm{[161].} \mathrm{Along} \mathrm{the} \mathrm{same} \mathrm{lines,} \mathrm{the}$ infusion of isoproterenol (a potent $\beta$-adrenergic stimulator) in hypertensive individuals leads to a dose-response increase in vWF [162]. The most likely explanation for these effects is that epinephrine binds to endothelial $\beta_{2}$ adrenergic receptors, stimulating the release of FVIII and vWF $[132,148]$.

As with platelets $[123,134]$, hypertensive status may be a mediating or moderating factor for coagulation responses to acute psychological stress. Exaggerations of stress reactivity of blood coagulation could provide one possible mechanism for the increased risk of atherothrombotic complications in individuals with essential hypertension. As such, Wirtz and colleagues [163] examined coagulant stress reactivity and recovery to the TSST in otherwise healthy middle-aged men with systolic and diastolic hypertension. FVII, FVIII, fibrinogen, and D-dimer were assessed from blood drawn immediately before stress, immediately after stress, and 20 and $60 \mathrm{~min}$ after stress. Compared to normotensive individuals and those with isolated systolic hypertension (i.e., $\mathrm{SBP} \geq 130$ ), those with diastolic hypertension (i.e., DBP $\geq 85$ ), either with or without systolic hypertension, showed greater FVII and D-dimer reactivity. Furthermore, those with diastolic hypertension had delayed recovery of coagulation measures; FVII, FVIII, and D-dimer were higher at $20 \mathrm{~min}$ and FVIII was higher at $60 \mathrm{~min}$ post-stress in those with diastolic hypertension compared to normotensive individuals. These effects remained when controlling for age, body mass index, resting mean arterial pressure, and resting coagulation factor levels. The findings of this study suggest that acute psychological stress causes a prothrombotic state that is greater in hypertensive than in normotensive individuals [163]. Thus, hypertensive individuals may be at a greater risk for developing premature atherosclerosis because of the magnified bursts of hypercoagulability that occur during times of stress and builds over a person's lifetime. Such an assertion is especially relevant given that, in healthy men, no habituation of any coagulation factor responses to acute stress occurred over 3 [143] or 4 weeks [137] weeks. Though no known study has examined the habituation of responses in hypertensive individuals, it seems feasible that such individuals would also not habituate to acute stressors, leading them to greater risk of developing premature atherosclerosis. Lending additional support to a lack of habituation are findings suggesting that individuals with greater chronic stress (e.g., Alzheimer caregivers having experienced more negative life events over 4 weeks) show greater coagulation responses to acute stress compared to caregivers who reported less negative life events [164]. Moreover, other markers of chronic stress, such as low socioeconomic status and low job control [142, 165], appear to be related to a hypercoagulable state during and/or immediately after a psychosocial stressor. Nevertheless, future studies should examine whether habituation of coagulation responses to acute stress occurs in hypertensive individuals.

It must be noted that many hemostasis markers assessed in acute stress studies have long half-lives, lasting for several hours to several days [166]. In some cases, they peak much later than when they are typically measured. For example, after an acute cardiovascular event, vWF levels typically become elevated at $24 \mathrm{~h}$ and peak $48-72 \mathrm{~h}$ before returning to normal 14 days after the event [167]. Therefore, it may not be appropriate to measure vWF immediately after a stressor. Given that acute psychological stress is purported to precipitate acute coronary syndromes, it stands to reason that such markers should be measured in the days following the laboratory stressor.

\section{Stress-Hemoconcentration and Hemostasis}

Notwithstanding sympathetic nervous system mechanisms, stress-hemoconcentration may play a crucial role in the observed increases in coagulation during acute psychological stress. SBP and DBP reliably increase during acute stress, which may push the plasma out of the vasculature into the interstitial spaces, causing hemoconcentration of coagulation factors. Although a small number of studies have examined hemoconcentration effects in stresscoagulation studies, these effects are often overlooked. This is the most important limitation of the majority of studies examining the effects of psychological stress on coagulation factors because, as shown in Table 1, the molecular weights of most coagulation factors examined in stress-coagulation studies are greater than $69 \mathrm{kDa}$ [168] and cannot pass freely through capillary pores. Specifically, the molecular weights of fibrinogen, prothrombin, FV, FVIII, FXI, FXII, and FXIII exceed this threshold [168]. Moreover, D-dimer has a molecular weight of $195 \mathrm{kDa}$ [169], and $\mathrm{vWF}$ is an extremely large molecule composed of numerous $250-\mathrm{kDa}$ subunits with a molecular weight often exceeding 20,000 kDa [170]. On the other hand, FVII has a molecular mass of approximately $50 \mathrm{kDa}$ [168]. Theoretically, FVII should be uninfluenced by stresshemoconcentration. However, one must also bear in mind whether assays are measuring concentrations of a clotting 
factor (e.g., FVII:ag) or its activity (e.g., FVII:C). It is feasible that a factor could become more active but have no change or even a decrease in concentration during acute stress.

Of the few studies that have examined stresshemoconcentration effects on coagulation, some have included hematocrit changes as a covariate when examining changes in the concentration of coagulation factors during acute psychological stress [149]. As such, it was concluded in these studies that the increases in coagulation factors during acute stress were independent of hemoconcentration. This approach, however, only controls for variation in changes in hematocrit rather than actually correcting for plasma volume shifts. Another approach to examining stress-hemoconcentration effects on coagulation has been to calculate Spearman correlations between change scores of hemoconcentration (i.e., hematocrit, hemoglobin, and plasma volume) and coagulation measures from baseline to immediately post-stress [144]. No significant relationships emerged with this method and, thus, the authors concluded that stress-hemoconcentration is an unlikely explanation for the coagulation response to stress. However, the relationships in this study pointed in the right direction for stresshemoconcentration effects and the authors acknowledge that significant associations may have been detected with a larger sample. Furthermore, correlations are not nearly as powerful as arithmetic adjustment for plasma volume shifts [72].

Only one known coagulation study has arithmetically adjusted for stress-induced plasma volume shifts [18]. In this study, it was reported that stress-hemoconcentration significantly altered the plasma levels of prothrombotic measures in response to the TSST. Specifically, fibrinogen, FVII, FVIII, FXII, and vWF levels all became elevated immediately after the TSST relative to baseline when there was no adjustment for plasma volume shifts. However, when taking plasma volume shifts into account, none of these increases remained significant. In contrast, fibrinogen and FVII levels even decreased significantly when correcting for hemoconcentration, which is consistent with studies examining changes in these factors during exercise [171]. However, given that FVII has a molecular weight of $50 \mathrm{kDa}$, it is puzzling why FVII showed this pattern of results.

Without correction for plasma volume shifts, APTT showed a shortening trend in this study as well, which suggests faster initiation of the intrinsic pathway of blood coagulation during acute stress, but PT did not change, suggesting that acute stress had no effect on clotting time of the extrinsic pathway. When adjusting for plasma volume shifts, however, a significant decrease was found for APTT, indicating faster clotting via the intrinsic pathway. On the other hand, PT was longer when correcting for plasma volume shifts, suggesting slower clotting via the extrinsic pathway [18].

When comparing baseline levels of coagulation measures to levels at $45 \mathrm{~min}$ post-stress (i.e., recovery), similar observations were noted, with the notable exception of FVIII which was the only clotting factor with elevations during recovery that survived arithmetic correction [18]. Moreover, FVIII levels remained higher when taking into account plasma volume changes during recovery. Together with the previous observation that FVIII remained elevated $2 \mathrm{~h}$ poststress compared to baseline levels [143], these results suggest that FVIII is actually or "genuinely" activated during the time immediately after acute psychological stress. Correcting for plasma volume changes in APTT and PT from baseline to recovery resulted in changes opposite to those seen between baseline and immediately post-stress levels. That is, APTT was prolonged and PT was shortened [18]. Given that APTT and PT are measures of time, these results, however, may be misleading and must be interpreted with extreme caution. Dill and Costill's [39] arithmetic correction for plasma volume shifts adjusts for the amount of plasma that leaves the vasculature during acute stress and should be used when examining changes in the concentration of a parameter. However, the arithmetic adjustment has no time component. Similarly, an arithmetic correction may be inappropriate when examining the activity or activation of clotting factors as opposed to concentrations. Changes in plasma volume may influence clotting time and clotting activity differently than the concentrations of clotting factors. Therefore, the use of mathematical correction for these measures is questionable.

A more biologically relevant method for correcting for hemoconcentration effects on clotting time and clotting activity may be to physically reconstitute plasma collected during a stressor with either plasma from rest or with physiological saline so that the plasma volume during stress becomes equivalent to the plasma volume at rest. A recent pilot study suggests that this may indeed be the case [172]. PT, APTT, FVIII:C, and fibrinogen were determined at baseline and immediately after a mental arithmetic stressor in ten young males. Plasma obtained immediately after the math task was reconstituted with baseline plasma and physiological saline equal to the amount of plasma lost during the stress-induced plasma volume shift. Paired $t$-tests showed that uncorrected PT and APTT immediately after the stressor were significantly shorter and that uncorrected FVIII:C was significantly higher than during baseline. Repeated-measures ANOVAs revealed that math APTT was not significantly shorter than baseline APTT when adjusting arithmetically for plasma volume changes or with either reconstitution technique. Similar to previous results [18], math PT became significantly longer than baseline PT when adjusting arithmetically for plasma volume shifts. 
However, PT was no longer significantly different than baseline PT when adjusting with either reconstitution technique. No overall effects were found for FVIII:C or fibrinogen, possibly due to low power arising from the small sample size [172]. Based on these preliminary results, mathematical adjustment appears to over-correct for plasma volume shifts when examining clotting time of the extrinsic pathway of coagulation (i.e., PT). Future studies should attempt to replicate and extend these findings to larger samples, different stressors, and different coagulation markers (e.g., D-dimer and vWF).

\section{Conclusions}

The elucidation of mechanisms linking acute stress to the triggering of atherothrombosis resulting in acute coronary syndromes is a crucial issue in psychohematology and cardiovascular behavioral medicine. One promising link is through elevated coagulation activity. The ensuing hypercoagulable state after acute stress may be more likely to cause an atherothrombotic event, especially when atherosclerosis or endothelial dysfunction is already present $[10$, 132]. Heightened sympathetic arousal could crucially shift the hemostatic balance toward a hypercoagulable condition in patients with atherosclerosis due to antithrombotic and fibrinolytic irregularities [10]. However, how heightened sympathetic arousal exerts its effects on hemostatic balance remains unclear. Possibilities include the activation of platelets and clotting factors by catecholamines and hemoconcentration of clotting factors resulting from plasma volume shifts. Studies attempting to address this issue have shown that acute stress results in a hypercoagulable state and that this state is probably exaggerated in hypertensive individuals. It is unclear whether the observed increases in the concentrations and activity of various coagulation factors during acute stress result from hemoconcentration or from actual activation of the coagulation system. Regardless of whether the elevated concentrations of hemostasis factors following acute stress are due to actual activation or to hemoconcentration, the endothelium becomes exposed to more of that cell. Such an intravascular environment has clear clinical implications. From a clinical standpoint, elevated clotting activity resulting from acute stress may promote an atherogenic vascular environment and is harmful no matter what the mechanism.

Different studies employing differing methods for correcting for stress-hemoconcentration effects have reported equivocal findings. Moreover, adjusting for hemoconcentration effects on parameters of coagulation time (i.e., PT and APTT) arithmetically [39] may over-correct, resulting in time becoming longer. It is plausible that the arithmetic correction for plasma volume shifts is also inappropriate when examining clotting activity during acute psychological stress. Therefore, arithmetic correction may only be useful when measuring concentrations. Future studies should examine whether alternative methods of adjusting for hemoconcentration effects, such as the reconstitution method previously discussed, are valuable.

Conflicts of Interest The authors have no conflicts of interest to disclose.

\section{References}

1. Kung HC, Hoyert DL, Xu J, Murphy SL. Deaths: Final data for 2005. Natl Vital Stat Rep. 2008;56. http://www.cdc.gov/nchs/ data/nvsr/nvsr56/nvsr56 10.pdf. Accessed February 13, 2009.

2. Rosamond W, Flegal K, Friday G, et al. Heart disease and stroke statistics-2007 update: A report from the American Heart Association Statistics Committee and Stroke Statistics Subcommittee. Circulation. 2007;115:69-171.

3. Greenland P, Knoll MD, Stamler J, et al. Major risk factors as antecedents of fatal and nonfatal coronary heart disease events. JAMA. 2003;290:891-897.

4. Rosengren A, Hawken S, Ouunpuu S, et al. Association of psychosocial risk factors with risk of acute myocardial infarction in 11,119 cases and 13,648 controls from 52 countries (the INTERHEART study): Case-control study. Lancet. 2004;364:953962.

5. Markovitz JH, Matthews KA. Platelets and coronary heart disease: Potential psychophysiologic mechanisms. Psychosom Med. 1991;53:643-668.

6. Patterson SM, Krantz DS. Effects of psychological and physical stress on platelet function. Homeost Health Dis. 1993;5:271-279.

7. Allen MT, Patterson SM. Hemoconcentration and stress: A review of physiological mechanisms and relevance for cardiovascular disease risk. Biol Psychol. 1995;41:1-27.

8. Patterson SM, Krantz DS, Gottdiener JS, Hecht G, Vargot S, Goldstein DS. Prothrombotic effects of environmental stress: Changes in platelet function, hematocrit, and total plasma protein. Psychosom Med. 1995;57:592-599.

9. de Boer D, Ring C, Wood M, et al. Time course and mechanisms of mental stress-induced changes and their recovery: Hematocrit, colloid osmotic pressure, whole blood viscosity, coagulation times, and hemodynamic activity. Psychophysiology. 2007;44:639-649.

10. von Känel R, Mills PJ, Fainman C, Dimsdale JE. Effects of psychological stress and psychiatric disorders on blood coagulation: A biobehavioral pathway to coronary artery disease? Psychosom Med. 2001;63:531-544.

11. Thrall G, Lane D, Carroll D, Lip GYH. A systematic review of the effects of acute psychological stress and physical activity on haemorheology, coagulation, fibrinolysis and platelet reactivity: Implications for the pathogenesis of acute coronary syndromes. Thromb Res. 2007;120:819-847.

12. Folsom AR, Wu KK, Rosamond WD, Sharrett AR, Chambless LE. Prospective study of hemostatic factors and incidence of coronary heart disease: The Atherosclerosis Risk in communities (ARIC) Study. Circulation. 1997;96:1102-1108.

13. Chan MY, Andreotti F, Becker RC. Hyprecoagulable state in cardiovascular disease. Circulation. 2008;118:2286-2297.

14. Rozanski A, Blumenthal JA, Davidson KW, Saab PG, Kubszanksy L. The epidemiology, pathophysiology, and management of 
psychosocial risk factors in cardiac practice: The emerging field of behavioral cardiology. J Am Coll Cardiol. 2005;45:637-651.

15. Rozanski A, Blumenthal JA, Kaplan J. Impact of psychological factors on the pathogenesis of cardiovascular disease and implications for therapy. Circulation. 1999;99:2192-2217.

16. Bhattacharyya MR, Steptoe A. Emotional triggers of acute coronary syndromes: Strength of evidence, biological processes, and clinical implications. Prog Cardiovasc Dis. 2007;49:353365.

17. Strike PC, Magid K, Brydon L, Edwards S, McEwan JR, Steptoe A. Exaggerated platelet and hemodynamic reactivity to mental stress in men with coronary artery disease. Psychosom Med. 2004;66:492-500.

18. von Känel R, Kudielka BM, Haeberli A, Stutz M, Fischer JE, Patterson SM. Prothrombotic changes with acute psychological stress: Combined effect of hemoconcentration and genuine coagulation activation. Thromb Res. 2009;123:622-630.

19. Hathcock JJ. Flow effects on coagulation and thrombosis. Arterioscler Thromb Vasc Biol. 2006;26:1729-1737.

20. Guyton AC, Hall JE. Textbook of Medical Physiology. 9th ed. Philadelphia: W.B. Saunders; 1996.

21. Ersley AJ. Blood and mountains. In: Winthrope MM, ed. Blood, pure and eloquent: A story of discovery of people, and of ideas. New York: McGraw-Hill; 1980.

22. Emery AC, Whitcomb WH, Frohlich ED. "Stress" polycythemia and hypertension. JAMA. 1974;229:159-162.

23. Isbister JP. The contracted plasma volume syndromes (relative polycythemias) and their haemorheological significance. Baillieres Clin Haematol. 1987;1:665-693.

24. Lawrence JH, Berlin NJ. Relative polycythemia: Polycythemia of stress. Yale J Biol Med. 1952;24:498-505.

25. Russell RP, Conley CL. Benign polycythemia: Gaisbock's syndrome. Arch Intern Med. 1964;114:734-740.

26. Ring C, Patterson SM, Bacon SL, Veldhuijzen van Zanten JJCS, Willemsen G, Carroll D. Reliability of hematocrit during rest and stress in healthy adults. Biol Psychol. 2008;77:63-68.

27. Holliday MA. Extracellular fluid and its proteins: Dehydration, shock, and recovery. Pediatr Nephrol. 1999;13:989-995.

28. Bacon SL, Ring C, Lip GYH, Carroll D. Increases in lipids and immune cells in response to exercise and mental stress in patients with suspected coronary artery disease: Effects of adjustment for shifts in plasma volume. Biol Psychol. 2004;65:237-250.

29. de Boer D, Ring C, Curlett AC, Ridley M, Carroll D. Mental stress-induced hemoconcentration and its recovery: A controlled study of time course and mechanisms. Psychophysiology. 2007;44:161-169.

30. Chien S. Blood rheology in myocardial-infarction and hypertension. Biorheology. 1986;23:633-653.

31. Brown BA. Hematology: Practices and principles. Philadelphia: Lea \& Febiger; 1993.

32. Patterson SM, Marsland AL, Manuck SB, Kameneva M, Muldoon MF. Acute hemoconcentration during psychological stress: Assessment of hemorheologic factors. Int J Behav Med. 1998;5:204-212.

33. Bazett HC, Sunderman FW, Doupe J, Scott JC. Climatic effects on the volume and composition of blood in man. Am J Physiol. 1940;129:69-83.

34. Stein HJ, Eliot JW, Bader RA. Physiological reactions to cold and their effects on the retention of acclimatization to heat. $J$ Appl Physiol. 1948;1:575-585.

35. van Beaumont W. Evaluation of hemoconcentration from hematocrit measurements. $J$ Appl Physiol. 1972;32:712-713.

36. Greenleaf JE, Convertino VA, Mangseth GR. Plasma volume during stress in man: Osmolality and red cell volume. $J$ Appl Physiol. 1979;47:1031-1038.
37. Costill DL, Branam L, Eddy D, Fink W. Alterations in red cell volume following exercise and dehydration. J Appl Physiol. 1974;37:912-916.

38. Costill DL, Fink WJ. Plasma volume changes following exercise and thermal dehydration. J Appl Physiol. 1974;37:521-525.

39. Dill DB, Costill DL. Calculation of percentage changes in volumes of blood, plasma, and red cells in dehydration. $J$ Appl Physiol. 1974;37:247-248.

40. Patterson SM, Krantz DS, Jochum S. Time course and mechanisms of decreased plasma volume during acute psychological stress and postural change in humans. Psychophysiology. 1995;32:538-545.

41. Garcia-Palmieri MR, Costas Jr. R., Cruz-Vidal M, et al. Urban-rural differences in coronary heart disease in a low incidence area: The Puerto Rico heart study. Am J Epidemiol. 1978;107:206-215

42. Sorlie PD, Garcia MR, Costas R, Havlik RJ. Hematocrit and risk of coronary heart disease: The Puerto Rico Heart Health Program. Am Heart J. 1981;101:456-461.

43. Cirillo M, Laurenzi M, Trevisan M, Stamler J. Hematocrit, blood pressure, and hypertension: The Gubbio Population Study. Hypertension. 1992;20:319-326.

44. Gagnon DR, Zhang TJ, Brand FN, Kannel WB. Hematocrit and the risk of cardiovascular disease - the Framingham Study: A 34-year follow-up. Am Heart J. 1994;127:674-682.

45. Brown DW, Giles WH, Croft JB. Hematocrit and the risk of coronary heart disease mortality. Am Heart J. 2001;142:657-663.

46. Kunnas T, Solakivi T, Huuskonen K, Kalela A, Renko J, Nikkari ST. Hematocrit and the risk of coronary heart disease mortality in the TAMRISK study, a 28-year follow-up. Prev Med. 2009;49:45-47.

47. Tibblin G, Bergentz SE, Bjure J, Wilhelmsen L. Hematocrit, plasma protein, plasma volume and viscosity in early hypertensive disease. Am Heart J. 1966;72:165-176.

48. Tarazi RC, Frohlich ED, Dustan HP. Plasma volume in men with essential hypertension. $N$ Engl J Med. 1968;278:762-765.

49. Julius S, Pascual A, Reilly K, London R. Abnormalities of plasma volume in borderline hypertension. Arch Intern Med. 1971;127:116-119.

50. Tarazi RC, Dustan HP, Frohlich ED. Relation of plasma to interstitial fluid volume in essential hypertension. Circulation. 1969;40:357-365.

51. Ibsen H, Leth A. Plasma volume and extracellular fluid volume in essential hypertension. Acta Med Scand. 1973;194:93-96.

52. Kobrin I, Frohlich EE, Ventura HO, Oigman W, Dunn FG, Messerli FH. Stable red cell mass despite contracted plasma volume in men with essential hypertension. $J$ Lab Clin Med. 1984;104:11-14.

53. Lebel M, Grose JH, Blais R.Increased hematocrit with normal red blood cell mass in early borderline essential hypertension. Clin Exp Hypertens A. 1989;11:1505-1514.

54. Texon M. The hemodynamic basis of atherosclerosis. Further observations: The linear lesion. Bull $N$ Y Acad Med. 1986;62:875-880.

55. Sabbah HN, Khaja F, Brymer JF, Hawkins ET, Stein PD. Blood flow in the coronary arteries of man: Relation to atherosclerosis. In: Liepsch DW, ed. Blood Flow in Large Arteries; Application to Atherogenesis and Clinical Medicine. Vol 15. New York: Karger; 1990:77-90.

56. Hahn C, Schwartz MA. Mechanotransduction in vascular physiology and atherogenesis. Nat Rev Mol Cell Biol. 2009; 10:53-62.

57. Rouleau L, Rossi J, Leask RL. The response of human aortic endothelial cells in a stenotic hemodynamic environment: Effect of duration, magnitude, and spatial gradients in wall shear stress. $J$ Biomech Eng. 2010;132:1-13. 
58. Koskinas KC, Chatzizisis YS, Baker AB, Edelman ER, Stone $\mathrm{PH}$, Feldman CL. The role of low endothelial shear stress in the conversion of atherosclerotic lesions from stable to unstable plaque. Curr Opin Cardiol. 2009;24:580-590.

59. van Beaumont W, Young HL, Greenleaf JE. Plasma fluid and blood constituent shifts during heat exposure in resting men. Aerosp Med. 1974;45:176-181.

60. van Beaumont W, Underkofler S, van Beaumont S. Erythrocyte volume, plasma volume, and acid-base changes in exercise and heat dehydration. J Appl Physiol. 1981;50:1255-1262.

61. Jung RC, Dill DB, Horton R, Horvath SM. Effects of age on plasma aldosterone levels and hemoconcentration at altitude. $J$ Appl Physiol. 1971;31:593-597.

62. Greenleaf JE, Bernauer EM, Young HL, et al. Fluid and electrolyte shifts during bed rest with isometric and isotonic exercise. J Appl Physiol. 1977;42:59-66.

63. Greenleaf JE, Shvartz E, Kravik S, Keil LC. Fluid shifts and endocrine responses during chair rest and water immersion in man. J Appl Physiol. 1980;48:79-88.

64. Greenleaf JE, van Beaumont W, Brock PJ, Morse JT, Mangseth GR. Plasma volume and electrolyte shifts with heavy exercise in sitting and supine positions. Am J Physiol Regul Integr Comp Physiol. 1979;236:206-214.

65. Thrall G, Lane D, Carroll, Lip. A systematic review of the prothrombotic effects of an acute change in posture: A possible mechanism underlying the morning excess in cardiovascular events? Chest. 2007;132:1337-1347.

66. Jern C, Wadenvik H, Mark H, Hallgren J, Jern S. Haematological changes during acute mental stress. Br J Haematol. 1989;71:153156.

67. Jern S, Jern C, Wadenvik H. 'Polycythaemia of stress' in subjects with Type A and Type B behavior patterns. $J$ Psychosom Res. 1991;35:91-98.

68. Muldoon MF, Herbert TB, Patterson SM, Kameneva M, Raible R, Manuck SB. Effects of acute psychological stress on serum lipid levels, hemoconcentration, and blood viscosity. Arch Intern Med. 1995;155:615-620.

69. Veldhuijzen van Zanten JJ, de Boer D, Harrison LK, et al. Competitiveness and hemodynamic reactions to competition. Psychophysiology. 2002;39:759-766.

70. VeldhuijzenvanZanten JJ, Ring C, Burns VE, Edwards KM, Drayson M, Carroll D. Mental stress-induced hemoconcentration: Sex differences and mechanisms. Psychophysiology. 2004;41:541-551.

71. VeldhuijzenvanZanten JJ, Thrall G, Wasche D, Carroll D, Ring C. The influence of hydration status on stress-induced hemoconcentration. Psychophysiology. 2005;42:98-107.

72. Muldoon MF, Bachen EA, Manuck SB, Waldstein SR, Bricker PL, Bennett JA. Acute cholesterol responses to mental stress and change in posture. Arch Intern Med. 1992;152:775-780.

73. de Boer D, Ring C, Carroll D. Time course and mechanisms of hemoconcentration in response to mental stress. Biol Psychol. 2006;72:318-324.

74. Kitahara Y, Imataka K, Nakaoka H, Ishibashi M, Yamaji T, Fujii J. Hematocrit increase by mental stress in hypertensive patients. Jpn Heart J. 1988;29:429-435.

75. Sakamoto H, Imataka K, Nishimurua H, Fujii J. Hematological and pressor hormone responses to mental stress in essential hypertensive patients: A comparison with isometric handgrip exercise. Hypertens Res. 1992;15:33-39.

76. Lowe GD. Should plasma viscosity replace the ESR? $\mathrm{Br} J$ Haematol. 1994;86:6-11.

77. Riddel Jr. JP, Aouizerat BE, Miaskowski C, Lillicrap DP. Theories of blood coagulation. J Pediatr Oncol Nurs. 2007;24:123-131.

78. Bennett JS, Shattil SJ. Platelet function. In: Williams WJ, Beutler E, Erslev AJ, Lichtman MA, eds. Hematology. 4th ed. New York: McGraw-Hill; 1990:1233-1250.
79. Holmsen MA. Metabolism of platelets. In: Williams WJ, Beutler E, Ersley AJ, Lichtman MA, eds. Hematology. 4th ed. New York: McGraw-Hill; 1999:1200-1233.

80. Owen J, Kaplan KL. Blood tests for the detection of thrombosis. Effects of blod flow and location of the sampling site. Ann NY Acad Sci. 1987;516:621-630.

81. Dahläck B. Blood coagulation. Lancet. 2000;355:1627-1632.

82. Cannon WB, Mendenhall WL. Factors affecting the coagulation time of blood: III. The hastening of coagulation by stimulating the splanchnic nerves. Am J Physiol. 1914;34:243-250.

83. MacFarlane RG, Biggs R. Observations on fibrinolysis: Spontaneous activity associated with surgical operations, trauma, etc. Lancet. 1946;2:862-864.

84. Davie EW, Ratnoff OD. Waterfall sequence for intrinsic blood clotting. Science. 1964;145:1310-1312.

85. Fareed J, Hoppensteadt DA, Leya F, et al. Thrombogenesis in myocardial infarction and related syndromes: The role of molecular markers in diagnosis and management. Clin Apply Thromb Hemost. 1999;5:78-91.

86. Lip GYH, Lowe GDO. Fibrin D-dimer: A useful clinical marker of thrombogenesis? Clin Sci. 1995;89:205-214.

87. Boisclair MD, Ireland H, Lane DA. Assessment of hpercoagulable states by measurement of activation fragments and peptides. Blood Rev. 1990;4:25-40.

88. Reininger AJ. Function of von Willebrand factor in haemostasis and thrombosis. Haemophilia. 2008;14(Suppl 5):11-26.

89. Hoffman M. Remodeling the blood coagulation cascade. $J$ Thromb Thrombolysis. 2003;16:17-20.

90. Malý MA, Tomašov $\mathrm{P}$, Hájek $\mathrm{P}$ et al. The role of tissue factor in thrombosis and hemostasis. Physiol Res. 2007;56:685-695.

91. Smith SA. The cell-based model of coagulation. J Vet Emerg Crit Care. 2009;19:3-10.

92. Kasthuri RS, Glover SL, Boles J, Mackman N. Tissue factor and tissue factor pathway inhibitor as key regulators of global hemostasis: Measurement of their levels in coagulation assays. Semin Thromb Hemost. 2010;36:764-771.

93. Steering Committee of the Physicians' Health Study Research Group. Final report on the aspirin component of the ongoing physicians' health study. $N$ Eng J Med. 1989;321:129-135.

94. Ross R. The pathogenesis of atherosclerosis - an update. $N$ Eng J Med. 1986;314:488-500.

95. Massberg S, Brand K, Grüner S, et al. A critical role of platelet adhesion in the initiation of atherosclerotic lesion formation. $J$ Exp Med. 2002;196:887-896.

96. Freedman JE, Loscalzo J. Platelet-monocyte aggregates: Bridging thrombosis and inflammation. Circulation. 2002;105:21302132.

97. Furman MI, Benoit SE, Barnard MR, et al. Increased platelet reactivity and circulating monocyte-platelet aggregates in patients with stable coronary artery disease. J Am Coll Cardiol. 1998;31:352-358.

98. Haines AP, Howarth D, North WR, et al. Haemostatic variables and the outcome of myocardial infarction. Thromb Haemost. 1983;50:800-803.

99. Meade TW, Cooper JA, Stirling Y, Howarth DJ, Ruddock V, Miller GJ. Factor VIII, ABO blood group and the incidence of ischaemic heart disease. $\mathrm{Br} J$ Haematol. 1994;88:601-607.

100. Thompson SG, Kienast J, Pyke SD, Haverkate F, van de Loo JC. Hemostatic factors and the risk of myocardial infarction or sudden death in patients with angina pectoris. $N$ Engl $\mathrm{J} \mathrm{Med}$. 1995;332:635-641.

101. Folsom AR, Aleksic N, Park E, Salomaa V, Juneja H, Wu KK. Prospective study of fibrinolysis and incident coronary heart disease: The Atherosclerosis risk in Communities (ARIC) Study. Arterioscler Thromb Vasc Biol. 2001;21:611-617. 
102. Aleksic N, Wang YW, Ahn C, Jueja HS, Folsom AR, Wu KK. Assessment of coronary heart disease risk by combined analysis of coagulation factors. Atherosclerosis. 2008;198:294-300.

103. Smith FB, Lee AJ, Fowkes FGR, Price JF, Rumley A, Lowe GDO. Hemostatic factors as predictors of ischemic heart disease and stroke in the Edinburgh Artery Study. Arterioscler Thromb Vasc Biol. 1997;17:3321-3325.

104. Thögersen AM, Jansson JH, Boman K, et al. High plasminogen activator inhibitor and tissue plasminogen activator levels in plasma precede a first acute myocardial infarction in both men and women: Evidence for the fibrinolytic system as an independent primary risk factor. Circulation. 1998;98:22412247.

105. Davies MJ. The contribution of thrombosis to the clinical expression of coronary atherosclerosis. Thromb Res. 1996;82:132.

106. Virmani R, Kolodgie FD, Burke AP, Farb A, Schwartz SM. Lessons from sudden coronary death: A comprehensive morphological classification scheme for atherosclerotic lesions. Arterioscler Thromb Vasc Biol. 2000;20:1262-1275.

107. Mills DCB, Roberts GCK. Effects of adrenaline on human blood platelets. J Physiol. 1967;193:443-453.

108. O'Brien JR. Some effects of adrenaline and anti-adrenaline compounds on platelets in vitro and in vivo. Nature. 1963;200:763-764.

109. Ponari O, Civardi E, Megha A, Pini M, Poti R, Dettori AG. In vitro and in vivo effects of adrenaline and phentolamine on platelet function. Thromb Haemost. 1978;40:428-437.

110. Alexander RW, Cooper B, Handin RI. Characterization of the human platelet $\alpha$-adrenergic receptor. J Clin Invest. 1978;61:1136-1144

111. Bremner JD, Krystal JH, Southwick SM, Charney DS. Noradrenergic mechanisms in stress and anxiety: II. Clinical studies. Synapse. 1996;23:39-51.

112. Dimsdale J, Moss J. Plasma catecholamines in stress and exercise. JAMA. 1980;243:340-342.

113. Larsson PT, Hjemdahl P, Olsson G, Egberg N, Hornstra G. Altered platelet function during mental stress and adrenaline infusion in humans: Evidence for an increased aggregability in vivo as measured by filtragometry. Clin Sci. 1989;76:369-376.

114. Larsson PT, Martinsson A, Olsson G, Hjemdahl P. Mental stress and adrenaline increase plasma growth factor activity in humans. Acta Physiol Scand. 1989;137:565-566.

115. Grignani G, Soffiantino F, Zucchella M, et al. Platelet activation by emotional stress in patients with coronary artery disease. Circulation. 1991;83(Suppl):128-136.

116. Naesh O, Haedersdal C, Hindberg I, Trap-Jensen J. Platelet activation in mental stress. Clin Physiol. 1993;13:299-307.

117. Levine SP, Towell BL, Suarez AM, Knieriem LK, Harris MM, George JN. Platelet activation and secretion associated with emotional stress. Circulation. 1985;71:1129-1134.

118. Rostrup M, Mundal HH, Kjeldsen SE, Gjesdal K, Eide I. Awareness of high blood pressure stimulates platelet release reaction. Thromb Haemost. 1990;63:367-370.

119. Patterson SM, Zakowski SG, Hall MH, Cohen L, Wollman K, Baum A. Psychological stress and platelet activation: Differences in platelet reactivity in healthy men during active and passive stressors. Health Psychol. 1994;13:34-38.

120. Markovitz JH, Matthews KA, Kiss J, Smitherman TC. Effects of hostility on platelet reactivity to psychological stress in coronary heart disease patients and in healthy controls. Psychosom Med. 1996;58:143-149.

121. Patterson SM, Matthews KA, Allen MT, Owens JF. Stressinduced hemoconcentration of blood cells and lipids in healthy women during acute psychological stress. Health Psychol. $1995 ; 14: 319-324$
122. Tomoda F, Takata M, Kagitani S, et al. Different platelet aggregability during mental stress in two stages of essential hypertension. Am J Hypertens. 1999;12:1063-1070.

123. Wallén NH, Held C, Rehnqvist N, Hjemdahl P. Effects of mental and physical stress on platelet function in patients with stable angina pectoris and healthy controls. Eur Heart J. 1997;18:807-815.

124. Larsson PT, Hjemdahl P, Olsson G, Angelin B, Hornstra G. Platelet aggregability in humans: Contrasting in vivo and in vitro findings during sympatho-adrenal activation and relationship to serum lipids. Eur J Clin Invest. 1990;20:398-405.

125. Malkoff SB, Muldoon MF, Zeigler ZR, Manuck SB. Blood platelet responsivity to acute mental stress. Psychosom Med. 1993;55:477-482.

126. Wallén NH, Goodall AH, Li N, Hjemdahl P. Activation of haemostasis by exercise, mental stress and adrenaline: Effects on platelet sensitivity to thrombin and thrombin generation. Clin Sci. 1999;97:27-35.

127. Andrén L, Wadenvik H, Kutti J, Hansson L. Stress and platelet activation. Acta Haematol. 1983;70:302-306.

128. Reid GJ, Seidelin PH, Kop WJ, et al. Mental-stress-induced platelet activation among patients with coronary artery disease. Psychosom Med. 2009;71:438-445.

129. Brydon L, Magid K, Steptoe A. Platelets, coronary heart disease, and stress. Brain Behav Immun. 2006;20:113-116.

130. Lande K, Kjeldsen SE, Os I, et al. Increased platelet and vascular smooth muscle reactivity to low-dose adrenaline infusion in mild essential hypertension. J Hypertens. 1988;6:219-225.

131. World Health Organization. 1999 World Health OrganizationInternational Society of Hypertension statement on management of hypertension. J Hypertens. 1999;17:151-183.

132. von Känel R, Dimsdale JE. Effects of sympathetic activation by adrenergic infusions on hemostasis in vivo. Eur J Haematol. 2000;65:357-369

133. Bacon SL, Ring C, Hee FL et al. Hemodynamic, hemostatic, and endothelial reactions to psychological and physical stress in coronary artery disease patients. Biol Psychol. 2006;71:162-170.

134. Steptoe A, Magid K, Edwards S, Brydon L, Hong Y, Erusalimsky J. The influence of psychological stress and socioeconomic status on platelet activation in men. Atherosclerosis. 2003;168:57-63.

135. Freedman RR, Embury J, Migaly P, et al. Stress-induced desensitization of $\alpha 2$-adrenergic receptors in human platelets. Psychosom Med. 1990;52:624-630.

136. Maes M, van Gastel A, Delmeire L, Kenis G, Bosmans E, Song C. Platelet $\alpha 2$-adrenoceptor density in humans: Relationships to stress-induced anxiety, psychasthenic constitution, gender and stress-induced changes in the inflammatory response system. Psychosom Med. 2002;32:919-928.

137. Hamer M, Gibson EL, Vuononvirta R, Williams E, Steptoe A. Inflammatory and hemostatic responses to repeated mental stress: Individual stability and habituation over time. Brain Behav Immun. 2006;20:456-459.

138. Aschbacher K, von Känel R, Mills PJ, et al. Longitudinal platelet reactivity to acute psychological stress among older men and women. Stress. 2009;12:426-433.

139. Cannon WB, Mendenhall WL. Factors affecting the coagulation time of blood: IV. The hastening of coagulation in pain and emotional excitement. Am J Physiol. 1914;34(251):260.

140. Cannon WB, Gray H. Factors affecting the coagulation time of blood: II. The hastening or retarding of coagulation by adrenalin injections. Am J Physiol. 1914;34:232-242.

141. Jern C, Eriksson E, Tengborn L, Risberg B, Wadenvik H, Jern S. Changes of plasma coagulation and fibrinolysis in response to mental stress. Thromb Haemost. 1989;62:767-771.

142. Steptoe A, Kunz-Ebrecht S, Rumley A, Lowe GDO. Prolonged elevations in haemostatic and rheological responses following 
psychological stress in low socioeconomic status men and women. Thromb Haemost. 2003;89:83-90.

143. von Känel R, Preckel D, Zgraggen L, et al. The effect of natural habituation on coagulation responses to acute mental stress and recovery in men. Thromb Haemost. 2004;92:1324-1335.

144. Zgraggen L, Fischer JE, Mischler K, Preckel D, Kudielka BM, von Känel $\mathrm{R}$. Relationship between hemoconcentration and blood coagulation responses to acute mental stress. Thromb Res. 2005;115:175-183.

145. Steptoe A, Marmot M. Psychosocial, hemostatic, and inflammatory correlates of delayed poststress blood pressure recovery. Psychosom Med. 2006;68:531-537.

146. Wirtz PH, Ehlert U, Emini L, et al. Anticipatory cognitive stress appraisal and the acute procoagulant stress response in men. Psychosom Med. 2006;68:851-858.

147. von Känel R, Dimsdale JE, Ziegler MG, et al. Effect of acute psychological stress on the hypercoagulable state in subjects (spousal caregivers of patients with Alzheimer's disease) with coronary or cerebrovascular disease and/or systemic hypertension. Am J Cardiol. 2001;87:1405-1408.

148. von Känel R, Mills PJ, Ziegler MG, Dimsdale JE. Effect of $\beta 2-$ adrenergic receptor functioning and increased norepinephrine on the hypercoagulable state with mental stress. Am Heart $J$. 2002;144:68-72.

149. von Känel R, Dimsdale JE, Adler KA, Patterson TL, Mills PJ, Grant I. Effects of depressive symptoms and anxiety on hemostatic responses to acute mental stress and recovery in the elderly. Psychiatry Res. 2004;126:253-264.

150. von Känel R, Kudielka BM, Hanebuth D, Preckel D, Fischer JE. Different contribution of interleukin-6 and cortisol activity to total plasma fibrin concentration and to acute mental stressinduced fibrin formation. Clin Sci. 2005;109:61-67.

151. Freyburger G, Trillaud H, Labrouche S, et al. D-dimer strategy in thrombosis exclusion - a gold standard study in 100 patients suspected of deep venous thrombosis or pulmonary embolism: 8 DD methods compared. Thromb Haemost. 1998;79:32-37.

152. Bozic M, Blinc A, Stegnar M. D-dimer, other markers of haemostasis activation and soluble adhesion molecules in patients with different clinical probabilities of deep vein thrombosis. Thromb Res. 2002;108:107-114.

153. Kirschbaum C, Pirke KM, Hellhammer DH. The "Trier Social Stress Test"- a tool for investigating psychobiological stress responses in a laboratory setting. Neuropsychobiology. 1993;28:76-81.

154. Dickerson SS, Kemeny ME. Acute stressors and cortisol responses: A theoretical integration and synthesis of laboratory research. Psych Bull. 2004;130:355-391.

155. Wirtz PH, Ehlert U, Emini L, et al. The role of stress hormones in the relationship between resting blood pressure and coagulation activity. J Hypertens. 2006;24:2409-2416.

156. Davis MC. Oral contraceptive use and hemodynamic, lipid, and fibrinogen responses to smoking and stress in women. Health Psychol. 1999; 18:122-130.

157. Kamarck TW, Debski TT, Manuck SB. Enhancing the laboratory-to-life generalizability of cardiovascular reactivity using multiple occasions of measurement. Psychophysiology. 2000;37:533-542.

158. Libre EP, Cowan DH, Watkins Jr. SP, Shulman NR. Relationships between spleen, platelets and factor 8 levels. Blood. 1968;31:358-368.

159. Prentice CRM, Forbes CD, Smith SM. Rise of factor VIII after exercise and adrenaline infusion, measured by immunological and biological techniques. Thromb Res. 1972;1:493-506.

160. Gader AMA, Clarkson AR, Cash JD. The plasminogen activator and coagulation factor VIII responses to adrenaline, noradrenaline, isoprenaline and salbutimol in man. Thromb Res. 1973;2:916.

161. Mannucci PM, Aberg M, Nilsson IM, Robertson B. Mechanism of plasminogen activator and factor VIII increase after vasoactive drugs. Br J Haematol. 1975;30:81-93.

162. von Känel R, Dimsdale JE, Adler KA, Dillon E, Perez CJ, Mills PJ. Effects of nonspecific $\beta$-adrenergic stimulation and blockade on blood coagulation in hypertension. $J$ Appl Physiol. 2003;94:1455-1459.

163. Wirtz PH, Ehlert U, Emini L, Rüdisüli K, Groessbauer S, von Känel R. Procoagulant stress reactivity and recovery in apparently healthy men with systolic and diastolic hypertension. $J$ Psychosom Res. 2007;63:51-58.

164. von Känel R, Dimsdale JE, Patterson TL, Grant I. Acute procoagulant stress response as a dynamic measure of allostatic load in Alzheimer caregivers. Ann Behav Med. 2003;26:42-48.

165. Steptoe A, Kunz-Ebrecht S, Owen N, et al. Influence of socioeconomic status and job control on plasma fibrinogen responses to acute stress. Psychosom Med. 2003;65:137-144.

166. Furie B, Furie BC. Molecular basis of blood coagulation. In: Hoffman R, Benz EJ, Shattil SJ, Furie B, Cohen HJ, Silberstein LE, McGlave P, eds. Hematology: Basic principles and practice. $3^{\text {rd }}$ ed. Philadelphia: Churchill Livingstone; 2000: 1783-1804.

167. Spiel AO, Gilbert JC, Jilma B. Von Willebrand factor in cardiovascular disease: Focus on acute coronary syndromes. Circulation. 2008;117:1449-1459.

168. Greenberg DL, Davie EW. Blood coagulation factors: Their complementary DNAs, genes and expression. In: Colman RW, Hirsh J, Marder VJ, Clowes AW, George JN, eds. Hemostasis and thrombosis: Basic principles and clinical practice. $4^{\text {th }}$ ed. Philadelphia: Lippincott Williams \& Wilkins; 2001:21-57.

169. Marder VJ, Francis CW. Plasmin degradation of cross-linked fibrin. Ann N Y Acad Sci. 1983;408:397-406.

170. Sadler JE. Biochemistry and genetics of von Willebrand factor. Annu Rev Biochem. 1998;67:395-424.

171. van den Burg PJ, Hospers JE, van Vliet M, Mosterd WL, Bouma BN, Huisveld IA. Changes in haemostatic factors and activation products after exercise in healthy subjects with different ages. Thromb Haemost. 1995;74:1457-1464.

172. Austin AW, Patterson SM, Ovre CD, Darr DL, Muhlenkamp LA. Stress-hemoconcentration effects on blood coagulation. Psychosom Med. 2010;72A. 